Anneliese Meis

Profesora Facultad de Teología

Pontificia Universidad Católica de Chile

\title{
Analogia donationis, la teología de lo absoluto en la obra de Hans Urs von Balthasar
}

Si bien hemos avanzado en las diversas exposiciones del Seminario hacia una profundidad insospechada en busca de una respuesta a la pregunta por la posibilidad de afirmaciones absolutas en una sociedad pluralista, quedan aspectos decisivos pendientes. Pues ¿se trata solo de afirmaciones absolutas o de la realidad absoluta? ¿de una sociedad pluralista por dentro o solo en sus expresiones? ¿No es que todos los aportes presupongan como obvio el nudo del problema propiamente tal, que no solo hay que afirmar o describir, sino pensar? Pero ¿cómo? No cabe duda de que en las afirmaciones absolutas se expresa la realidad absoluta para un enfoque realista acrítico. Pero ¿qué sucede cuando la crítica de la razón invierte la pregunta y lo absoluto no es la realidad, sino las categorías de la razón?

Dejando planteada la cuestión de la crítica a la crítica como sin solución inmediata, emerge otra cuestión más radical y contundente, que la ciencia suele obviar: ¿por qué hay algo y no la nada? En efecto, esta cuestión traspone el problema a la estructura misma del ser de lo que es en cuanto es y no tiene que ser, es decir, según la etimología del vocablo absolutus, aparece algo suelto de todo, lo absoluto y algo no suelto, lo relativo de modo irreconciliable, pues se es o no es. El es -esse-, sin duda, es plenitud y el no ser, privación (1).

Pero ¿estos opuestos son irreconciliables? O ¿no vale lo que Kant afirma respecto de la analogía que, inversamente a lo que se piensa, los opuestos se constituyen en una unión más firme, sólida, que los no opuestos, es decir, lo yuxtapuesto? (2). Balthasar todavía da un paso más cuando aborda el acontecer analógico en el ser, cual movimiento de un polo a otro, del ser al no ser y viceversa, de tal modo que la negatividad del no ser se torna positiva en la medida en que es don (3) y el

(1) LOTZ B., Ser (“Esse”), en BRUGGER W., Diccionario de Filosofía, Barcelona 1958; FREDE M.; KOBUSCH Th., u.o., Sein; Seiendes HWP 9 (1995) 170-233; KELLER A., Ser, en KRINGS H., u.o., Conceptos fundamentales de Filosofía III, Barcelona 1979, 380-398.

(2) KANT E., Prolegomena, 233 (A176).

(3) WIERCINSKI A., Hermeneutik der Gabe. Die Wechselwirkung von Philosophie und Theologie bei Hans Urs von Balthasar, en KASPER W., (ed.) Logik der Liebe und Herrlichkeit Gottes. Hans Urs von Balthasar im Gespräch. Festgabe für Karl Kardinal Lehmann zum 70. Geburtstag, Mainz 2006, 350-370. PEREZ HARO E., El misterio del Ser. Una Mediación entre Filosofía y Teología en Hans Urs von Balthasar, Barcelona 1994, 451 pp. Es llamativa la atención que presta la 
ser es comprendido en cuanto analogia donationis (4). Pero ¿en qué medida tal analogia donationis, permaneciendo siempre analogia entis (5), posibilita afirmaciones absolutas en la sociedad pluralista? Esto se pretende mostrar, siguiendo la argumentación balthasariana, en tres pasos, elaborados sobre una base estadística, sorpresivamente extensa y multifacética, del campo semántico, que ocupa lo absoluto en toda la obra de Hans Urs von Balthasar (6).

\section{LO ABSOLUTO, UNA POSIBILIDAD ÓNTICA DRAMÁTICA}

La cuestión de la posibilidad de afirmaciones absolutas en una sociedad pluralista involucra el ser en cuanto fundamento absoluto de todo cuanto es y la índole plural de sus múltiples expresiones. Pero ¿el ser es unívoco?, ¿es concepto?, ¿es Dios? Y si no lo es, sino, en términos de Balthasar, "plenitud atravesada por la nada" -Durchnichtigte Fülle- (7) ¿cómo pensar esta plenitud en cuanto pregunta por el ser, su condición gratuita y la apertura de la razón al todo del ser y el ente relativo?

Filosofía actualmente a la comprensión del don y su relación con el ser: Cf. MARION J.L., Acerca de la donación. Una perspectiva fenomenológica, Buenos Aires 2005, 97 pp; DALFERTH I.U., UMSONST. Vom Schenken, Geben und Bekommen, Studia Theologica 59 (2005) 83-103. GILBERT P., Gratuité, Nouvelle Revue Theologique 127 (2005) 251-265; HENAFF M. Argumentaire: du don céremoniel a la politique de la reconnaissance, Esprit (2002) 159-165; HOFFMANN V., Die Gabe der Anerkennung. Ein Beitrag zur Soteriologie aus der Perspektive des Werkes von Paul Ricoeur, Theologie und Philosophie 81 (2006) 503-528.

(4) Si bien el vocablo analogia abunda y las referencias al don y la donación son frecuentes en la obra de Hans Urs von Balthasar, la fórmula analogia donationis no se encuentra como tal en los escritos balthasarianos, sino representa un neologismo, creado a partir de la traducción latina de Ef 4, 7 por CASARELlA P., Analogia donationis: Hans Urs von Balthasar on the Eucharist...secundum mensuram donationis Christi (Eph 4, 7) Philosophy of Theology 11 (1998) 147-177: indica "la unidad de dos realidades, libremente constituidas: el don del amor de Dios y nuestra respuesta". El presente trabajo no se restringe a esta definición, desarrollada por Casarella en un contexto eucarístico, sino usa la fórmula en un sentido propiamente balthasariano en relación con la cuestión del ser.

(5) Cf. BALTHASAR H.Urs von, Von den Aufgaben der katholischen Philosophie in der Zeit, 1.ed. 1946; reeditado, Freiburg i.Brsg.1998, 77 pp.: se pretende entender "como se acepta, desde la absolutez de la verdad de Cristo, revelada en cuanto persona y la fe en ella como roca inconmovible, en la cual se apoya todo saber restante, la despreocupación en la relativización también de los intentos más grandes del pensar de la humanidad: relativización no en el sentido de un cuestionamiento escéptico de toda verdad intramundana, sino en el sentido de un abrir todos los sistemas encerrados en sí, a modo de pecado original y por eso, excluyéndose mutuamente, para el servicio universal a la única verdad cristiana. En este actuar los Padres solo toman en serio la afirmación de la analogia entis, según la cual todo ser mundano y por eso también sus propiedades trascendentales, entre las cuales se cuenta la verdad, solo puede llamado ser en un sentido secundario análogo como ser, condicionado por el primario",

(6) BALTHASAR Hans Urs von, Herrlichkeit. Eine theologische Ästetik, Band I, II, III, I, Teil I, Teil II; III, II, Teil I, Teil II, Dritte Auflage, Einsiedel 1988(= H); Theodramatik. Band I, II, Teil I ; Teil II, III, IV Einsiedeln 1980(=TD); Theologik Band I; II, III, Einsiedeln 1985(=TL); Epilog Einsiedeln 1987(=Ep). Die Absolutheit des Christentums und die Katholizität der Kirche, en KASPER W.(ed), Absolutheit des Christentums (QD, 79) Freiburg-Basel-Wien 1977, 131-156- Cf. BALTHASAR H. Urs von., Mein Werk. Durchblicke, Einsiedeln 1990, 113 pp.; BALTHASAR H. Urs von, Bibliographie 1925-2005. Neubearbeitet von Cornelia Capol und Claudia Müller, Freiburg i.Br. Einsiedeln 2005, 223 pp. GUERRIERO E., Hans Urs von Balthasar. Eine Monographie, Einsiedeln 1993, 438 pp. O’DONNELL J., Hans Urs von Balthasar, 2.ed., London, New York 2000, 166pp. SCOLA A., Hans Urs von Balthasar: un estilo teológico, Madrid 1997, 127 pp. Herrlichkeit III/1 768. 


\section{a. La pregunta por el ser y su fundamento absoluto}

La pregunta acerca del ser afecta al fundamento más íntimo gracias al cual todo ente es. Revelar esto que es lo más profundo constituye la esencia de la filosofía occidental desde los griegos, pero también de la teología, ya que "la plenitud absoluta del ser de Dios eligió al hombre como ente y recipiente en el que revela al mundo su plenitud interior", de tal modo que "este se experimenta a sí mismo como englobado por y en manos de lo que le rebasa..." (8)

\section{El Ser ¿se manifiesta?}

Con Balthasar cabe preguntar en Gloria: “¿por qué las criaturas, que viven en el Ser absoluto, habrán de tener los ojos cerrados cuando el Ser absoluto abre los ojos en el seno de ellas? ¡El mundo despierta en el alma junto con Dios!” (9). Pero advierte el teólogo suizo: "Aquí, donde en diversos grados de claridad brilla la totalidad del ser en cada uno de los seres, es donde se presenta el concepto de la forma", que "es una representación "contracta" del "absoluto"... en cuanto que en su campo cerrado trasciende y domina las partes en que se articula" (10). Junto con la relevancia de la forma cabe prestar atención a un más allá de ella.

Pues el teólogo suizo acota: "Todo dependerá entonces de que nosotros sigamos los elementos conocidos en el "mundo"...como razón y como voluntad (libre) hasta su convergencia en el punto inaccesible y escurridizo del Absoluto: Dios es... Sobre-razón, pero es también e igualmente Sobre-voluntad..." (11). Pero como "El absoluto ser-otro de Dios se revela preferentemente en el hecho de estar el mundo compuesto de contrastes e incluso de contradicciones" (12), "se niega que puede alcanzarse desde abajo el 'conceptus absolutus' de Dios" (13), como lo pretende el idealismo "del saber absoluto" (14).

(8) H 1164 (G 1 158): Eben deshalb kann ihn Gottes Seinsfülle zum Wesen und Gefäss erwählen, in welchem er für die Welt Seine innere Fülle offenbaren kann.- Cf. H I 433 (G 1 155): Er erfährt sich als umgriffen und überantwortet.

(9) H II (Juan de la Cruz) esp 158.

(10) H III I 30(G 4 32):Hier, wo in verschiedenen Graden der Deutlichkeit je das Ganze des Seins am einzelnen Seienden aufleuchtet, bietet sich der Begriff der Gestalt an. Er meint eine als solche erfasste, in sich stehende begrenzte Ganzheit von Teilen und Elementen, die doch zu ihrem Bestand nicht nur einer "Umwelt", sondern schliesslich des Seins im ganzen bedarf und in diesem Bedürfen eine (wie Cusanus sagt) "kontrakte" Darstellung des "Absoluten" ist, sofern auch sie auf ihrem eingeschränkten Feld seine Teile als Glieder übersteigt und beherrscht” Cf. FIELDS S., The Singular as Event: Postmodernism, Rahner, and Balthasar, American Catholic Philophical Quarterly 77 (2003) 93-111.

(11) H III I 259(G 4 261-262):Alles wird daran hängen, dass wir die Konvergenz dessen, was in der "Welt" als Vernunft und als (freier) Wille bekannt ist, auf den unerreichbaren Fluchtpunkt des Absoluten hin verfolgen: Gott ist (in sich und in seinem Sich-mitteilen) Über-Vernunft, er ist aber ebenso Über-Wille.

(12) H III I 312 (G 4, 313):Das absolute Anders-sein Gottes erscheint vornehmlich daran, dass die Welt aus Gegensätzen, ja aus Widersprüchen zusammengesetzt ist Cf. H III I II I: "ein Gott der absoluten Subjektivität (Eckhart) und des absoluten freien Wollens(Ockham)".

(13) H III I II (G 5 228): Dass der "conceptus absolutus" Gottes von unten erreichbar sei, wird zwar geleugnet.

(14) H III I II 587(G 4 314): weist aber unweigerlich auf den kommenden Idealismus voraus Cf. Ep 84(101): Alle Religionen ausser dem Alten Testament waren und sind Versuche, dieser Tragik zu 
De ahí que Balthasar concluye, pasando de Gloria a la Teodramática, "en el hecho de que en el ente puede hacerse presente y desvelarse el ser, de que... el ente se encuentra en la luz absoluta y así puede ser leído e interpretado, y de que precisamente el carácter único de un ser hace brillar de modo particularmente evidente la indivisible irrepetibilidad del ser en su conjunto, radica... el fundamento de la revelación de Dios en la figura singular de Cristo y la posibilitación transcendental para que el hombre pueda percibirla" (15).

\section{El Ser ¿se da?}

Constata Balthasar: "Dado que la realidad que así sale al encuentro no establece ninguna frontera frente al fundamento absoluto, hay no solo infinitas posibilidades del fundamento absoluto para que este se deje percibir en el que sensiblemente lo encuentra, sino que se abre también su posibilidad de conservarse a sí mismo de modo absoluto y definitivo" (16). "Con esto emerge irresistiblemente la pregunta más radical por el sentido, que el mundo científico-técnico no puede plantear, pero que se plasma en interrelación con el misterio inagotable de las religiones y del Dios vivo como "dador de sentido" (17).

Esto lleva a que "nuestra pregunta se hace doble. El hombre puede comprenderse de un lado en la diferencia entre ente (mundo) y ser (absoluto, Dios); pero puede de otro lado aspirar a borrar esta diferencia excluyendo metodológicamente lo absoluto (Dios) e intentando concentrar la totalidad del sentido en el ámbito intramundano. Pero aun cuando él se sitúa en la diferencia, surge todavía la pregunta sobre cómo puede él subsistir con su dramaticidad trágica delante del absoluto" (18). Permaneciendo "en el interior de la diferencia entre el ser mundano y el

entfliehen, durch Unsterblichkeitserklärung der Seele, die dem Leibgefängnis entflieht -noch beliebt in neuzeitlichem Idealismus-, durch Wiederverkörperung, aber um ihr allgemach zu entgehen, durch Preisgabe der Individuation ins Absolute oder in eine zukünftige ideale Gesellschaft hinein. Der Widerstand gegen alle diese Ausbruchsversuche im Alten Bund gehört zum Erstaunlichsten in der Geistesgeschichte der Menschheit.

(15) TD II 1 21(2, 26): Darin , dass im Wesen das Sein im ganzen anwesen und sich enthüllen kann, dass...das Wesen im absoluten Licht steht und darin gelesen und gedeutet werden kann, und dass gerade die Einzigartigkeit eines Wesens die unteilbare Einmaligkeit des Seins im ganzen besonders evident aufleuchten lässt, liegt...die Begründung der Offenbarung Gottes in der Einzelgestalt Christi und die transzendentale Ermöglichung für den Menschen, sie wahrzunehmen. cf. PONGA S., Le Christ Universale Concretum chez Hans Urs von Balthasar Nouvelle Revue Theologique 127(2005) 587-603.

(16) TD II 1 21(2, 26): H.J. VEWEYEN: "Insofern die so begegenende Wirklichkeit keine Grenze gegen den absoluten Grund setzt, bleiben nicht nur unendlichen Möglichkeiten des absoluten Grundes, sich selbst in sinnlich Begegnenden zur Vernehmung zu bringen, sondern es ist auch seine Möglichkeit eröffnet, sich selbst in ihr absolut und endgültig zu gewähren”.

(17) TD II I 37s (2, 43): Die wissenschaftlich-technische Welt mit ihrem"methodischen Atheismus" erscheint, falls sie absolut gesetzt wird, d.h. den Sinn des Daseins innerhalb ihrer Geschlosssenheit sucht, als die Negation des Absoluten über die Welt, jenes Absoluten, das in vielen Religionen als das unerforschliche Mysterium oder als das Göttliche, in den biblischen Religionen als der lebendige Gott das für das menschliche Dasein letztlich Sinnspendende ist, die erhoffbare Erfüllung der "unterhalb" der Wahlfreiheit offenen absoluten Kapazität des endlichen Geistes und damit der Ausblick auf eine Überwindung der Tragik des einzelnen menschlichen Daseins.

(18) TD II I 38(2, 43):So gesehen, verdoppelt sich unsere Frage. Der Mensch kann sich einerseits in der Diffenrez zwischen Seiendem (Welt) und Sein(Absolutem, Gott) verstehen; er kann anderseits diese Differenz zu tilgen trachten, indem er das Absolute(Gott methodisch auszuklammern und 
absoluto ¿garantiza a la dramaticidad de la existencia el derecho inscrito en su forma concreta?" pregunta Balthasar y contesta: "Si el concepto de absoluto se toma en serio, hay que responder negativamente, y esto une a primera vista ateísmo (en todas sus formas impías y devotas) y teísmo en una paradójica unidad... Menos que las olas sobre la profundidad eternamente inmóvil del mar: pues las olas pertenecen con su movimiento al mar, pero el destino de los mortales no pertenece a lo absoluto. Vivenciar o describir lo finito sobre el trasfondo de lo absoluto puede colocar en una agitada tensión" (19).

Sin embargo, es cierto que "entre ambos extremos existen transiciones misteriosas sobre todo cuando lo absoluto lanza intermitentemente irritaciones entre la nada y el todo...se abre un camino que confiesa algo positivo respecto a lo absoluto: un "camino de la sabiduría"... Pero también este camino... solo se hace reconocible en su negatividad: su rastro pasa por donde la forma finita es negada y mira a lo absoluto" (20). Ahora "puede plantearse la cuestión central: ¿Cómo tendría que configurarse la relación entre el mundo y lo absoluto, entre el hombre y Dios, para que la nivelación de la caducidad y de la muerte no haga paralizarse desde dentro la dramaticidad de la existencia?...La respuesta no es construible desde el hombre". Sin embargo, “...es necesario que en la concepción del absoluto deba contenerse otro momento. Debe haber habido la concepción de un Dios, que, a pesar de su carácter absoluto, participa interna, divina y absolutamente en la dramaticidad de la existencia mortal" (21).

El Ser ¿se dice?

Dando el paso a la Teológica, Balthasar afirma: "El ser que se le hace presente en la autoconciencia no es el ser en el sentido absoluto. Pues "se le hace evidente

allen Sinn im Innenraum der Welt einzubringen sucht. Aber auch wenn er sich in die Differenz stellt, erhebt sich noch die Frage, wie er mit seiner tragischen Dramatik vor dem Absoluten bestehen kann. Cf. LUCIANI RIVERO R. F., El Misterio de la diferencia. Un estudio tipológico de la analogía como estructura originaria de la realidad en Tomás de Aquino, Erich Przywara y Hans Urs von Balthasar y su uso en teología trinitaria (Analecta Gregoriana 285. B, 101) Roma 2002, 628 pp.

(19) TD II I 38s (2, 44): Aber verbürgt denn ein Verharren innerhalb der Differenz zwischen Weltsein und Absolutem der Dramatik der Existenz schon das ihrer Gestalt eingeschriebene Recht?...Man muss das, falls der Begriff des Absoluten ernst genommen wird, verneinen, und dies bindet zunächst Atheismus (in all seinen unfrommen und frommen Spielformen) und Theismus zu einer pardoxen Einheit zusammen...Weniger als die Sturzwellen über den ewig unbewegten Tiefen des Meeres; denn die Wellen gehören mit ihrer Bewegung zu Meer, aber das Geschick der Sterblichen gehört dem Absoluten nicht an. Endliches aus dem Hintergrund des Absoluten zu erleben oder zu schildern kann in eine erregende Spannung versetzen.

(20) TD II I 40 (2, 45): Und doch: zwischen beiden Extremen gibt es geheimnisvolle Übergänge; dort zu mal, wo das Absolute infeststellbar zwischen dem Nichts und dem Alles schillert... kann sich doch ein Weg bahnen, der angesichts des Absoluten etwas Positives besagt: ein "Weg der Weisung”...Doch auch dieser... Weg wird nur an seiner Negativität erkennbar: seine Spur läuft dort, wo endlichen Gestalt negiert und zum Absoluten hin durchschaut wird..

(21) TD II I 41(2, 46): Von dieser Grenze her kann die Frage der Mitte gestellt werden: wie müsste das Verhältnis zwischen der Welt und dem Absoluten, zwischen dem Menschen und Gott gestaltet sein, wenn die Nivellierung der Vergänglichkeit und des Todes nicht von innen her die Dramatik der Existenz lähmen soll?...Die Antwort ist vom Menschen her nicht konstruibar...deshalb muss, damit dies möglich sei, der Vorstellung des Absoluten noch ein anderes Moment einwohnen...Es muss die Vorstellung eines Gottes gewesen sein, der unbeschadet seiner Absolutheit an der Dramatik der sterblichen Existenz inneren, göttlichen, absoluten Anteil nimmt”. 
que el ser absoluto tiene que ser un ser medido por sí mismo, presente a sí mismo...Así pues ciertamente está abierta para el sujeto la verdad que, en cuanto verdad, siempre roza la esfera de lo absoluto, infinito y por lo tanto divino" (22). "El primer punto de contacto entre objeto y sujeto son las imágenes que ... son lo absolutamente manifiesto (23)... y remiten "al problema de lo universal y lo especial...y la absoluta unidad de especie o género...". Pero "existe entre ambos una diferencia que no es posible separar de un recíproco incluirse, en el cual lo otro siempre representa un excedente, un resto inagotable" (24)...Al revelarse, el ente exhibe su plenitud cada vez mayor y con ello su irreductible misterio" (25).

Balthasar, por eso, insta: "hay que atreverse a empezar con algo mucho más universal, a saber, con la pregunta sobre en qué modo el ser absoluto de Dios, que solo puede existir como trinitario..., se refleja en el ser del mundo. Se debe preguntar con toda seriedad acerca de la imago Trinitatis in ente creato... Puesto que la pregunta por el ser como tal es la pregunta fundamental de la metafísica, es inevitable para el teólogo" (26).

Sintetizando, puede apreciarse cómo lo absoluto se entreteje con la pregunta por el ser que se articula a la luz de un fundamento más allá del ser y que como tal se manifiesta, da y dice en sus infinitas posibilidades por medio de la forma, es decir, en la diferencia entre el ser y el ente. Por lo cual Dios no es el ser, sino que lo da, de modo absolutamente gratuito.

\section{b. La condición de absoluta gratuidad}

Para Balthasar no cabe duda de que en la realidad reina "un misterio que está más allá de la pobreza y de la riqueza... el ser en su magnífico, absoluto e inefable

(22) TL I 44 (1, 52): Das Sein, das ihm im Selbstbewusstsein erschlossen ist, ist nicht Sein schlechthin. Denn die Lichtung seiner selbst, in der es sich selbst ergreift und darin erfährt, was Sein ist, lichtet ihm nicht das Sein im ganzen, sondern lichtet das Sein nur soweit, dass es begreift, dass alles Sein an sich selbst gelichtet sein muss. In der punkhaften Identität von Sein und Bewusstsein, in dessen Licht das Subjekt das Mass sowohl seiner selbst wie des zu messenden Objekts gewinnt, wird ihm klar, dass das absolute Sein ein von sich selbst gemessenes, sich selbst gegenwärtiges und darum ein Selbstbewusssein sein muss.

(23) TL I 145(1, 135): Die Bilder sind das schlechthin Offenbare.Sie zu leugnen, ist unmöglich: "schlechthin" tiene el sentido de "absolutamente".

(24) TL I 171-172 (1, 154-155): In dieses Geheimnis des Allgemeinen und Besonderen weist uns somit das Problem von Wesen und Erscheinung zurück. Das Allgemeine ist keine blosse Abstraktion aus einer Ähnlichkeit der Individuen; denn eine solche Ähnlichkeit würde niemals die absolute Einheit der Art oder Gattung in allen Individuen verbürgen...es besteht zwischen beiden eine Unterscheidung ohne mögliche Trennung, ein gegenseitiges sich -Einschliessen, bei dem das jeweils Andere einen Überschuss darstellt, einen Rest, der nicht aufgeht.

(25) TL I $175(1,157)$ : Das Seiende erweist in seiner Offenbarung seine je-grössere Fülle, und damit sein unaufhebbares Geheimnis.

(26) TL II 159 (2, 169-170): Vielmehr muss gewagt werden, mit etwas viel Universalerem einzusetzen, nämlich mit der Frage, wie sich das absolute Sein Gottes, das es -auch wenn die opera Dei "ad extra"(falls es ein "extra" Gottes gäbe) gemeinsam erfolgen-nur als ein trinitarisches geben kann, im Sein der Welt widerspiegelt. Es muss allen Ernstes nach der imago Trinitatis in ente creato gefragt werden, auch wenn diese Frage in der Theologiegeschichte bisher nicht oft gestellt worden ist. Da die Frage nach dem Sein als solchem die Grundfrage der Metaphysik ist, ist sie für den Theologen nicht zu umgehen." Cf. HOLZER V., Philosophie de 1'Etre et Statut de la Theologie fondamentale. Hans Urs von Balthasar, Revista Española de Teología 65 (2005) 493-514. 
triunfo sobre la nada... pero solo por una vez puede esta plenitud expandirse de manera absoluta: en Dios..." (27). La mención tanto de "la plenitud y de la nada" evoca un aspecto fundamental de la comprensión balthasariana de lo absoluto no idéntico con el ser, pero enlazado con él, en cuanto autoirradiación, autodonación y libertad absoluta.

La autoirradiación del ser

En Gloria el teólogo suizo se detiene en "Este mysterium de la autoirradiación expansiva del ser" que "... solo se hace transparente, cuando, desde el ámbito de la revelación bíblica, resplandece ante nosotros la libertad absoluta... pero no en el sentido de que el Dios personal salga al encuentro del hombre como un ente delimitado al encuentro de otro ente sino en el sentido de que la libre profundidad personal del ser absoluto que se da, saca finalmente a la luz el secreto de la creación... Dios es el absolutamente Otro solo en cuanto non-aliud, no otro" (28).

Esto lleva a Balthasar a la intuición de que: Si Dios "libremente crea el mundo y así comunica al mundo... algo del estilo de su libertad, de su capacidad donante, libre, sosegada, y si esta libertad dadora no merece otro nombre que el de amor: ¿de qué otra materia "podría entonces "ser" Dios, sino de "amor"? Cualquier otro intento de aproximarse al "Absoluto", más allá de la diferencia ontológica, distinto de este, tendría que valorar al "Absoluto" menos que a sus derivados” (29).

La autodonación del ser

Cuando Balthasar insiste en la Teodramática que: "El autexousion de la libertad finita encierra un momento de carácter absoluto -Absolutheit- una "infinita finitud" por tanto, que ni puede recobrar su propio origen (en la medida en que la libertad finita se reconoce en sí misma como "donada") ni... alcanzar su fin en un

(27) H III I II 955 (G 5 574-75): Es waltet also im Wirklichen ein Geheimnis jenseits von Fülle und Armut, das sich durch jedes der beiden zwar richtig und doch nur unzureichend ausdrückt. Nichts ist reicher und füllehafter als das Sein in seinem unfasslich herrlichen absoluten Sieg über das Nichts (Sein ohne diese Fülle ist gar nicht denkbar, es geisterte nur in ungedachten Denkansätzen), aber diese Fülle kann sich nur einmal absolut ausbreiten: in Gott.

(28) H III I II 955s(G 5 574-75):Dieses...Mysterium des strömenden Sich-Ausleuchten des Seins, das allein die Möglichkeit einer Welt erklärt (nämlich die paradoxe Existenz "neben" dem allesfüllenden und keiner Sache bedürftigen unendlichen Sein), gelangt zu seiner Durchsichtigkeit doch erst, wenn, aus dem Raum der biblischen Offenbarung, die absolute Freiheit (als Geistigkeit und Personhaftigkeit Gottes) hereinleuchtet: aber nicht so, dass der personale Gott dem Menschen wie ein Seiendes abgegrenzt einem andern Seienden-mit Überspringen des Seins-entgegenträte(wie man, den Alten Bunbd philosophielos auslegend, meinen könnte) sondern so, dass die personale Tiefe des sich schenkenden absoluten Seins erst das Schöpfungsgeheimnis, die "vierte Differenz", ins Helle bringt. Gott ist der Ganz-Andere nur als Non-Aliud, das Nicht-andere (Cusanus).

(29) H III I II 965(G 5, 586): Wenn er ungenötigt die Welt schafft, und ihr so, mit ihrem nicht nötigenden Ungenötigtsein, etwas von der Artung seiner Freiheit und frei-gelassenen Gebenskraft mitgibt, und wenn diese schenkende Freiheit keinen andern Namen verdient als Liebe: aus welchem andern Grunde könnte Gott dann "sein" als "aus" Liebe? Jeder andere Versuch, das "Absolute" jenseits der ontologischen Differenz anzunähern, als dieser müsste dem "Absoluten" weniger zuschreiben als dem davon Abkünftigen. 
recorrido de los distintos bienes y valores que se hallan en el mundo, sean personales o no" (30), proyecta la condición de absoluta gratuidad de la libertad finita.

El teólogo suizo explica: "Si su condición de absoluta gratuidad condiciona la latencia del donante, esta latencia, sin embargo, no puede ser total. En la ley interna, proveniente del "estar emplazado y centrado en el camino", puede reconocer el don del donante. Esta luz lucirá con la mayor claridad allí donde el que ha sido dado a sí mismo puede comprenderse en la luz original del don absoluto, es decir, en la esencia de un Dios que se ha dado, ya desde siempre, en el Hijo eterno como arquetipo de la creación" (31). Balthasar, sin embargo, admite: "hay que contar siempre con una modificación sobrenatural de la naturaleza espiritual del hombre que tiene ya una capacidad natural de transcenderse a lo absoluto" (32).

Balthasar concluye: "Para decirlo brevemente, entonces esta apertura hacia arriba, que es el órgano de una definitiva donación de sentido, se pone al servicio de la búsqueda de sentido a nivel horizontal, con lo que se origina la tentación de atribuir significado absoluto a los fragmentos de sentido relativos encontrados en la historia y entregarse sin reserva a esos productos humanos... Sobre ideas que son ciertamente finitas y por ello solo en parte verdaderas, se condensa la nostalgia, inherente al espíritu humano, por lo absoluto, lo que da origen a lo que se ha designado "superestructura ideológica" (33).

La libertad absoluta

Balthasar insiste en la Teológica: “Aquí se esclarece también el enigma de por qué una libertad creada... no puede liberarse a sí misma respecto a Dios... Esta idea

(30) TD II I 206(2, 210): Das autexousion der endlichen Freiheit enthält ein Moment der Absolutheit, ein "unendliche Endlichkeit" als, die aber weder ihren eigenen Ursprung einholen kann, sofern sich endliche Freiheit"als gegeben" vorfindet, noch (deshalb) ihr Ziel im Durchlaufen sämtlicher in der Welt vorfindlichen Güter und Werte, seien sie personal oder nicht, zu erreichen vermag. Cf. BIELER M., The Future of the philosophy of Being, Communio, Internacional Catholic Review, 26(1999) 455-485: BIELER M., Freiheit als Gabe. Ein schöpfungstheologischer Entwurf, Freiburg 1991.

(31) TD II I 259(2, 261): Endliche Freiheit...hat an der unendlichen Freiheit ihr Ge-setz und ihre Weisung, die ihr nicht äusserlich zukommen, sondern innerlich eingeschrieben sind. Wenn ihr echtes Gegebensein ein Latenz des Gebers bedingt, so kann diese Latenz doch keine vollständige sein: im innern Licht des "auf den Weg ge-setzt-und ge-wiesen-Seins" ist die Gabe des Gebers erkennbar. Dieses Licht wird dor am hellsten scheinen, wo er Sich-Geschenkte sich im Ur-Licht der absoluten Gabe verstehen darf: im Wesen eines Gottes, der sich immer schon an den ewigen Sohn als Urbild der Schöpfung verschenkt hat.

(32) TD III 377(3, 375) Man muss deshalb immer schon mit einer übernatürlichen Modifikation der bereits naturhaft auf das Absolute transzendierenden Geistnatur des Menschen rechnen. Auch im Rahmen dieser Annnahme bleiben jedoch mehrere Fagen offen.

(33) TD III 68 (4, 70) Und nunmehr wird, um es kurz zu sagen, diese Offenheit nach oben, die das Organ abschliessender Sinngebung ist, in den Dienst der Sinnfindung in der Horizonalen gestellt, wodurch die Tendenz entsteht, relativen Sinnfragmenten in der Geschichte absolute Bedeutung zuzulegen und sich solchen Gebilden dann auch mit Haut und Haar zu verschreiben:Mit dem(nachchristlichen) Entstehen verschiedener geschichtsphilosophiscer Entwürfe entsteht allererst das, was man im strengen Sinn als "Ideologie" bezeicnhen kann. Über gewisse endliche und deshalb nur teilhaft wahre Ideen wird die dem Menschengeist inhärierende Sehnsucht nach dem Absoluten gestülpt, wodurch das entsteht, was man als "ideologischen Überbau" bezeichnet hat. 
se perfecciona bíblicamente: como comprensión de la condición derivada (donada) de la libertad creada, cuando aquello de donde procede se hace eficaz en ella, a fin de liberarla de la obstinación en su propia "absolutidad" (34).

"Se mostró que una auténtica libertad creada...solo se puede entender en su finitud, pues ha comenzado y debe elevarse ella misma a término, desde un infinito hacia el que trasciende... El misterioso acontecimiento de la creación, de que la libertad absoluta de Dios es tan libre que puede crear auténtica, si bien relativa, libertad, queda excedido por el acontecimiento de la alianza. En esta, la absoluta libertad de Dios se regala, y, dentro de este regalo, espera y posibilita también la libre respuesta de amor de la otra parte, sin forzarla en lo más mínimo" (35).

\section{c. La paradoja de la apertura al todo del ser y el ente relativo}

Si bien el ser humano en cuanto ente relativo está abierto a todo ser y "siendo así que el motus de la libertad es inseparable de la causa sui, y que en la voluntad anida un deseo natural (desiderium naturale) de una autoposesión plena y perfecta, que debería coincidir con la "posesión" del ser como tal, aparece la paradoja...: el hombre aspira a completarse en un Absoluto que él, aún siendo causa sui, no puede llegar a alcanzar ni por sí mismo ni con la ayuda de un ser y un bien finito cualquiera" (36).

Apertura a todo el ser

En Gloria Balthasar constata: "El acto fundamental metafísico es el amor dentro de la diferencia del ser... el acto fundamental cristiano es el amor dentro de la diferencia Dios-mundo... amor significa aquí siempre el acto total del hombre, que incluye en sí tanto la totalidad corpóreo-espiritual como, en particular, la razón recipiente. Como razón metafísica percibe la relación informulable del ente y del

(34) TL III 249-250 (3, 269): Hier erhellt sich auch das Rätsel, warum eine geschöpfliche Freiheit(wenn sie wirklich Freiheit ist) sich Gott gegenüber nicht selbst befreien kann...Diese Einsicht vollendet sich biblisch: als Einsicht in die Herkünftigkeit(Geschenktheit) des geschaffenen Freiheit, wenn das, wovon sie herkommt, in ihr wirksam wird, um sie aus der Vertrotzung in die eigene "Absolutheit" zu lösen.

(35) TL III 248 (3, 267): Dort wurde gezeigt, dass echte geschöpfliche Freiheit (als autoexousion; Thomas, sui causa) sich in ihrer Endlichkeit -denn sie hat begonnen und muss sich selber erst vollenden -nur von einem Unendlichen her, worauf sie transzendiert, verstehen kann, das Platon das Gute, die Bibel den absolut freien Gott nennt. Das geheimnisvolle Schöpfungsereignis, dass die absolute Freiheit Gottes so frei ist, dass sie echte, wenn auch relative Freiheit erschaffen kann, wird überhöht vom Bundesereignis, worin Gottes absolute Freiheit sich hinschenkt und innerhalb dieses Geschenkes die freie Liebesantwort des Partners sowohl erwartet wie ermöglicht, ohne sie im geringsten zu erzwingen.

(36) TD II I 204(2, 208): Weil aber der “motus” der Freiheit von der “causa sui” untrennbar ist, im Willen also eine naturhafte Sehnsucht (desiderium naturale) nach dem vollendeten, erschöpflichen Selbstbesitz liegt, der mit dem "Besitz" des Seins als solchem zusammenfallen müsste, kommt das thomanische (von Henri de Lubac wieder ins volle Licht gesetzte) Paradox zustande, dass der Mensch sich in einem Absoluten zu vollenden strebt, das er, obschon "causa sui", aus sich selbst und mit der Erreichung irgendeines endlichen Seienden und Guten nicht zu erreichen vermag.Das eben macht nach Thomas des Menschen Würde aus. 
ser, como razón cristiana percibe la libre palabra de Dios, la palabra del amor absoluto, que se expresa en esta relación como medium" (37).

En efecto, "el hombre solo puede darse enteramente una vez. Su entrega es respuesta a Aquel que es el fundamento de su poder ser...solo por las decisiones supremas del amor el mundo llegará a ser "amoroso", nunca por las facilidades de la técnica. En la diferencia ontológica brota... un misterio irreductible de plenitud y vaciedad, y de este modo una inutilidad ineludible de su existencia, la cual solo pasando por esta vanidad... puede experimentar la gratuidad... del ser absoluto" (38).

El punto absoluto y el ente relativo

En la Teodramática Balthasar explicita lo anterior al afirmar: "el hombre no puede desprenderse de su referencia vertical hacia lo absoluto, pero tampoco puede encajar a lo absoluto en su finitud mediante su propia actividad...intentará actualizar su orientación hacia lo absoluto que le rebasa..." No se puede "secularizar la nostalgia de lo absoluto de la que procede, pues esta nostalgia es lo nuclear del hombre y el manantial del que brota el postulado del sentido en general, del sentido sin más, también en el historia horizontal" (39). De tal modo, el hombre no puede dejar de plantear preguntas sobre el enigma que él mismo es... y que el sentido encierra en sí una pretensión de absolutez, sin que consiga presentar la plenitud de esta pretensión a la vista de la temporalidad y de la muerte" (40).

(37) H III I II 965s(G 5, 587): Der metaphysische Grundakt ist die Liebe innerhalb der Seinsdifferenz (also der dritten, die beiden ersten in sich schliessenden Differenz); der christliche Grundakt ist die Liebe innerhalb der Gott-Welt-Differenz (also der vierten, die drei ersten in sich schliessenden Differenz): Liebe bedeutet hier jedesmal den totalen Mensch-Akt, der sowohl die geistleibliche Ganzheit wie insbesondere die vernehmende Vernunft in sich schliesst. Als metaphysische Vernunft vernimmt sie das unformulierbare Verhältnis des Seienen und des Seins, als christliche Vernunft das in diesem Verhältnis als Medium sich aussprechende freie Gotteswort absoluter Liebe.

(38) H III I II 981 (G 5, 602): Denn ein Mensch kann sich nur einmal ganz verschenken. Seine Hingabe aber gilt, als Antwort, Dem, der der Grund seines Seindürfens ist; Dem, der im letzten nicht Sachen und Gegenstände von ihm will; sondern ihn. Fili, praebe mihi cor tuum. Durch noch so perfektionierte Sachen wird der Mensch sein Herz nie verbessern; nur durch letzte Entscheidungen der Liebe, nie durch Erleichterungen der Technik wird die Welt "amorisiert" werden. In der ontologischen Differenz bricht, wie wir sahen, ein unrückführbares Geheimnis von Fülle und Nichtigkeit auf, und damit eine unaufgebbare Vergeblichkeit alles Daseins, das nur durch dieses Umsonst(vanité) hindurch das Umsonst (gratuité) des absolluten Seins erfahren kann. Ist es vergeblich, so kann ihm vergeben, so kann es vergeben werden. Und nur dann kann es mit dem absoluten Wort selber mitsprechen:"Wie auch wir vergeben..."

(39) TD III 69(4, 71): Da der Mensch sich seiner vertikalen Beziehung zum Absoluten nicht entschlagen, aber das Absolute auch nicht durch eigenes... Tun in seine Endlichkeit hinein bannen kann, wird er ...versuchen, seine Hinordnung auf das ihn übersteigende Absolute, ...zu vergegenwärtigen...(Solche Vergöttlichungen von Endlichem) können nachchristlich säkularisiert werden, nicht aber die Sehnsucht nach dem Absoluten, der sie entstammmen, denn diese Sehnsucht ist das Herzstück des Menschen und der Quellpunkt, von dem aus das Postulat von Sinn überhaupt, ja Sinn schlechthin auch in die horizontale Geschichte hinein ergeht.

(40) TD III 69 (4, 71): Er kann deshalb nicht aufhören, über sich zu rätseln, weil er weiss, was Sinn ist (auch wenn er ihn nicht mehr findet), weil Sinn einen Anspruch von Absolutheit in sich hat, er aber die Erfüllung dieses Anspruchs angesichts von Zeit und Tod nie vorweisen kann. 
La filosofía... "consigue en el mejor de los casos alcanzar el horizonte de un absoluto abstracto, delante del cual (sea que se lo piense como transcendente o como inmanente) se despliega la historia" (41). Acota Balthasar: "Puede quedarse fascinada en este punto en el que lo finito en su poquedad debería desposarse con lo infinito salvador, o lo relativo con lo absoluto, pero al constituirse a priori, ese punto se equivocaría con mayor gravedad precisamente en la medida en que pretendía adivinarlo o apresarlo" (42). "El punto absoluto (la apertura de la razón al todo del ser, de lo verdadero y de lo bueno...) puede, aunque continuamente se le escapa de las manos (lo "bueno" más allá de toda ousia), pero a pesar de todo en virtud de sus reflejos en lo finito, ser representado por medio de múltiples proyecciones del pensamiento: ...desde la perspectiva de la relación entre el punto absoluto y el ente relativo: como lo único que de verdad cuenta y frente a lo cual todo lo caduco es insustancial, como la norma que todo lo caduco anhela reflejar y reproducir, como la ley absoluta que secretamente habita en todo lo finito..." (43).

Para el teólogo suizo: "El hecho de que al reflexionar sobre su propio ser y al mirar más allá de su existencia a una norma absoluta del bien, alcanza un criterio para realizar el bien de modo finito, apunta hacia la bondad de la meta a la que se dirige. De este modo percibe con claridad que el bien (como la verdad) tienen que ver con su autoposesión y su autorrealización, porque descubre implícita la idea de que ese absoluto, del que se ve como una imagen, tiene que ser el mismo autoposesión, es decir, espíritu" ...."Y ello en mayor medida resulta claro si se ve que ese absoluto no es bueno solamente para mí, sino para todo lo que se sabe debido a él..." (44).

Balthasar concluye: "En este punto preciso radica la paradoja última del hombre...Así como un hombre necesita de la libre apertura de otro para ser él mismo, pero no puede forzar esta autoapertura, del mismo modo él (estructurado y proyectado sobre y hacia la verdad y el bien absoluto) necesita de la autoapertura de Dios pero sin que pueda postular por sí mismo... Por lo cual... en el desiderium

(41) TD III 70 (4, 72): Die Philosophie erreicht...bestenfalls den Horizont eines abstrakten Absoluten, vor dem ( ob es nun mehr transzendent oder auch immanent gedacht wird) das Geschichtliche sich abspielt.

(42) TD III $71(4,73)$ Er kann zwar gebannt auf den Punkt starren, an dem das untergehende Endliche sich mit dem rettend Unendlichen, das Relative sich mit dem Absoluten vermählen müsste, aber er muss in der Vorweg-Konstruktion dieses Punktes sich nur tiefer verirren, gerade wenn er ihn von sich her zu erraten, gar anzuziehen sich vermisst.

(43) TD III 96-97(4, 99): Der Absolutpunkt -Offenheit der Vernunft auf das Ganze des Seins, des Wahren und Guten, Notwendigkeit, sich aufgrund des eigenen Wesens danach auszurichten und davon richten zu lassen- kann in seiner Entzogenheit(das "Gute jenseits aller Ousia"), aber mit seinem Hineinscheinen in alles Endliche durch vielfältige Denk-Proyektionen vorgestellt werden... Vom Verhältnis zwischen dem Absolutpunkt und del Relativ-Seienden aus: als das einzig ernsthaft Zählende, dem gegenúber alles Vergängliche wesenlos ist, als die Norm, die das vergängliche trachten muss in sich abzuspiegeln und nachzubilden, als das allem Endlichen heimlich innewohnende absolute Gesetz“.

(44) TD III 127(4, 130):Und ebenso: dass es sich, auf sein eigenes Wesen reflektierend und über seine Existenz auf eine absolute Norm des Guten ausblickend, einen Massstab für endlicherweise zu verwirklichendes Gutes gewinnt, weist es auf das Schlechthin-Gut-Sein seines Zieles hin. Dabei aber wird ihm klar, dass das Gute (wie das Wahre) mit seinem Selbstbesitz, seinem Selbstverwirklichtsein zu tuen hat, weshalb der Gedanke naheliegen müsste, jenes Absolute, als dessen Bild es sich versteht, müsse selber Selbstbesitz, damit Geist sein....Dies um so mehr, als dieses Absolute ja nicht nur für mich gut ist, sondern für alles, das sich ihm zu verdanken hat. 
visionis natural, en el deseo de conocer a Dios como él es en sí mismo, no hay necesidad de reconocer un momento sobrenatural; aunque... pueda... decirse que Dios desde siempre haya manifestado algo de su intimidad y haya querido capacitar al hombre para que pueda aprehenderlo" (45).

¿Cómo puede la unidad absoluta ser trinitaria?

Cuando en la Teológica Balthasar se refiere brevemente a la verdad, constata: "Precisamente aquí, donde se debe hablar de la verdad, será el lugar para reflexionar... sobre los trascendentales... Con ello, se hará visible objetivamente -pues juntos rigen totalmente el ser entero-, no solo su inseparabilidad... su recíproca compenetración y presuposición, sino también el trascendental fundante de la unidad trascendental... se ha de abordar...¿Cómo puede la unidad absoluta ser trinitaria? Aquí se demostrará que de la unidad como trascendental únicamente se puede tratar cuando previamente se hayan tratado temáticamente los demás trascendentales" (46).

En sintesis, la dramaticidad de la posibilidad de emitir afirmaciones absolutas en una sociedad pluralista queda a la vista, pero cabe ahondar en cuál es el origen fundante de esta posibilidad. Y ¿qué aporta la comprensión de este origen por la revelación del Dios Trino a la posibilidad de afirmaciones absolutas?

\section{DIOS TRINO, ORIGEN FUNDANTE DE LAS AFIRMACIONES ABSOLUTAS}

Para Balthasar el problema central de la posibilidad de las afirmaciones absolutas es: "cómo Dios puede ser "todo" desde el momento que existe además un "mundo" (de innumerables cosas finitas); o también: cómo Dios puede ser todo en toda cosa sin ser formalmente el ser de las cosas" (47). Sostiene el teólogo suizo

(45) TD III 130(4, 132): An dieser genauen Stelle liegt das letzte Paradox des Menschen...So wie...ein Mensch auf die freie Selbsterschliessung des Mitmenschen angewiesen ist, um selbst zu sein, und er dies Selbsterschliessung doch nicht erzwingen kann, so sehr ist er (auf das absolute Wahre und Gute hin entworfen und angelegt ist) auf die Selbsterschliessung Gottes angewiesen, ohne sie von sich aus postulieren zu können...Deshalb (betont de Lubac mit Recht), dass im naturhaften desiderium visionis, im Sehen, Gott so zu kennen, wie er in sich selber ist, noch keinerlei übernatürliches Moment zu liegen braucht, was ganz unabhänig davon festgestellt werden kann (und muss), das Gott von jeher schon etwas von seinem Innern kundtun und den Menschen befähigen wollte, es ausffassen zu können.

(46) TL I VII-VIII(1, 11-12): Hier nun, wo von der Wahrheit die Rede sein soll, wird es der Ort sein, über die behandelten Transzendentalien nochmals ausdrücklicher zu reflektieren, dabei wird sachgemäss-da sie ja gemeinsam das ganze Sein durchwalten-nicht nur ihre Untrennbarkeit (vgl. Platón, Philebos 64e), ihre gegenseitige Durchdringung und Voraussetzung sichtbar werden, sondern damit auch das grundlegende Transzendentale der Einheit, auf dessen geschöpfliche Struktur im ersten Band (169f, 186ff, 201, 283) reflektiert wurde, auf deren göttliche Struktur ("Wie kann die absolute Einheit trinitarisch sein?") eingegangen werden soll. Dabei wird sich zeigen, dass von Einheit als Transzendentale überhaupt erst gehandelt werdenn kann, wenn die übrigen Transzendentalien vorweg thematisch geworden sind.

(47) H III I II 894 (5, 515):... war das zentrale Problem, wie Gott "Alles" sein kann, wenn es aussderdem eine "Welt" (aus unzähligen endlichen Dingen) gibt; oder auch: wie Gott alles in allem sein kann, ohne formelll das Sein der Dinge zu sein. 
que solo puede tratarse del ser en cuanto "imagen de este absoluto, al cual se siente referido". De tal modo que da razón a Tomás al afirmar que "el conocimiento de las personas divinas es necesario para una correcta comprensión de las cosas creadas" (48).

\section{a. La parábola del absoluto}

En la Teodramática Balthasar no deja lugar a dudas que "En cuanto ser que debe su existencia, no puede la conciencia identificarse con el ser, sino solo como una "imagen" de este absoluto..." (49). Según Balthasar, "apoyándose en esta afirmación, G. Siewerth intentará deducir "especulativamente todas las diferencias solo de la distinción real de la subsistencia divina" e iluminar(las) tanto en su múltiple nulidad como en su estructura mediadora". Consecuentemente, determinará la diferencia en Dios como diferencia entre "ser y subsistencia" (de las hipóstasis) con lo cual la diferencia entre ser y esencia no es totalmente decisiva, y se escapa a la obligatoriedad hegeliana de definir el Uno absoluto en la alteridad de la esencia finita y hacerlo venir a sí mismo o recluirlo en el "superser" trascendente" (50).

Balthasar, por eso, acierta: "A través del desposeimiento, la potencia, la alteridad, el no-ser, el cambio, domina lo positivo de un movimiento infinito del ser hacia la realidad, que como tal no procede de la forma, sino que acontece en lo íntimo del ser mismo. Así, solo esto es la pura parábola del absoluto" (51), que se plasma a partir de su origen fundante absoluto, en Sí relativo, donde la índole parabólica del ser se vuelve, particularmente, nítida, cuando se trata del bien. En definitiva, es amor, cuya fuente es el Padre, se realiza como eterno sí del Hijo y queda garantizado en cuanto diferencia que el Espíritu Santo mantiene abierta entre el Padre y el Hijo.

(48) TL II 170 (2, 180): So erst ist dieses das reine Gleichnis des Absoluten. Damit behält Thomas recht: "Die Kenntnis der göttlichen Personen war notwendig zu einem rechten Verständnis der geschaffenen Dinge".-Para la relación de Balthasar con Tomás de Aquino, cf. SCHINDLER D. C., Towards a non-possessive concept of Knowledge: on the relation between reason and love in Aquinas and Balthasar, Modern Theology 22 (2006) 577-608; ENDERS M., Grundzüge philosophischer und theologischer Hermeneutik der Wahrheit in der "Theologik" des Hans Urs von Balthasar, Philotheos 3 (2003) 274-293.

(49) TD III 127(4, 129): Als sich verdanken-müssendes Sein kann sich das Bewusstsein nicht als mit dem absoluten Sein identisch setzen, sondern mur als ein"Bild" dieses Absoluten, auf das es in seibnem ihm ungreifbaren "Woher" und "Wohin" notwendig bezogen ist.

(50) TL II 170 (2, 180): Er wird folgerichtig die Differenz in Gott als eine solche zwischen "Sein und Subsistenz"(der Hypostasen) bestimmen, wodurch die Differenz zwischen Sein udn Wesen nicht die letztentscheidende ist und man dem hegelschen Zwang entkommt, "das absolute Eine in der Andersheit endlicher Wesen sich definieren und zu sich selbst kommen zu lassen oder es ins transzendente "Übersein" in sich abzuschliessen" Cf. TOURPE E., Le Thomisme ontologique de Gustav Siewerth, Ferdinand Ulrich et Hans André a 1'arriere-plan de la Pensée Balthasarienne. "Die vielen Freunde, deren Namen ich jetzt verschweige..." Revista Española de Teología 65 (2005) 467-491.

(51) TL II 170 (2, 180) Durch die Entäusserung, die Potenz, die Andersheit, das Nichtsein, die Veränderung hindurcu waltet das Positive einer unendlichen Bewegung des Seins zur Realität, die als solche nicht aus der Form her kommt, sondern im Innern des Seins selbst sich ereignet. So erst ist diese das reine Gleichnis des Absoluten". 


\section{b. El Padre, plenitud fontal del amor absoluto}

El teólogo suizo se detiene en la Teodramática en "El gesto con el que el Padre expresa y entrega toda la divinidad... Y este se sigue dando, a pesar de que la misma comunicación sea un acontecimiento de amor absoluto, cuya felicidad consiste no solo en dar alguna cosa, sino a sí mismo. El hecho de abarcar de un solo golpe de vista ambos aspectos, no autoriza, sin embargo, a contemplar a la Trinidad de un modo unilateral, como el "escenario" de la "bienaventuranza" absoluta, pero abstrayéndose del dolor real y por lo mismo obviando el "peso serio" de la separación y de la muerte..." (52).

"El amor es fuerte como el abismo": no es más fuerte que este, porque el abismo no es posible más que en el marco englobante de la distinción absoluta y real del Padre y del Hijo". Pero "Es necesario, si queremos llegar a entender con alma creyente el drama originario de Dios que no está ni sometido al tiempo ni a un proceso, seguir reflexionando. Cuando el Padre se expresa y se da sin reservas, ni se pierde ni se agota con el don, a pesar de que, por otra parte, no se reserva nada de sí y para sí. Él es la total esencia de Dios en esta autodonación; así se manifiesta en todo este proceso toda la infinita potencia y a la vez impotencia de Dios, que no sabría ser Dios de otra manera que en esta "kenosis" intradivina..." (53).

\section{c. El eterno sí del Hijo}

Balthasar afirma en Gloria que "el entre... Cristo hombre, a quien amamos, nos manifiesta la apertura del Ser absoluto como amor sustancial y nos dice con ello que también el mundo es intrínseca y estructuralmente amable" (54). "Aunque solo el Hijo es hombre, su humanidad será necesariamente expresión de toda la esencia trinitaria de Dios, pues solo así puede ser la revelación del Ser absoluto...Y esto, de tal manera que la relatividad de lo humano... no queda sofocada ni violentada por la simultaneidad de lo absoluto divino" (55).

El teólogo suizo insiste en la Teodramática: “... el Hijo no puede existir ni poseer el carácter absoluto de la divinidad más que bajo el modo de recreación de

(52) TD III 302 (4, 301):Die Gebärde, mit der der Vater die ganze Gottheit ausspricht und dahingibt. Und dies, obschon die gleiche Mitteilung ein Geschehen absoluter Liebe ist, deren Seligkeit im Verschenken nicht nur von etwas, sondern seiner selbst besteht. Dies gibt, wenn beides zugleich ins Auge gefasst wird, das Recht nicht, die Trinität einseitig als das "Spiel" absoluter, aber vom realen Schmerz abstrahierender, somit des "Ernstes der Trennung und des Todes entbehrender "Seligkeit" anzusehen.

(53) TD III 302s (4, 301): "Stark wie die Hölle ist die Liebe”, nein: stärker als diese, da Hölle nur umfangen von der absoluten und wirklichen Trennung von Vater und Sohn möglich ist. cf. HOLZER V., Les implications métaphysic-religieuses d'une dramatique trinitaire chez Hans Urs von Balthasar, Gregorianum 86 (2005) 308-329.

(54) H I 186 (G 1, 176): Die Offenbarheit des Seins als des absoluten wird uns von dem Seienden, das der Mensch Christus ist, den wir lieben, als substantielle Liebe kundgetan, das weltliche Sein somit als innerlich liebehaft strukturiert, wie es Augustin im 2.Teil seines De Trinitate zu erweisen versucht.

(55) H I 441(G 1, 408): obschon nur der Sohn Gottes Mensch ist, wird sein Menschsein notwendig Ausdruck des ganzen dreieinigen Gottwesens; nur so kann er die Offenbarkeit des absoluten Seins sein...Und doch so, dass die Relativiät des Menschlichen (als Geschöpflichen) nicht erdrückt und vergewaltigt erscheint durch die gleichzeitige Absolutheit des Göttlichen, 
esta unidad de omnipotencia e impotencia (desde el Padre).Y esta recepción comprende a la vez dos cosas: primero el hecho de saberse donado (presupuesto absoluto de toda posibilidad de entrega del Hijo al mundo) y, después, la acción de gracias filial (eucarística) por la consustancialidad del ser-Dios" (56). "La acción de gracias proclamada por Él es el eterno sí del Hijo a su propia condición de ser don, desde su absoluta igualdad divina, un sí a la kenosis originaria del Padre, que une en sí la omnipotencia (de poder dar todo) y la impotencia (puesto que nada es tan verdaderamente poderoso como el don)" (57).

Balthasar prosigue: "Llegar hasta el fin de la verdad significa para el Hijo responder adecuadamente a la autodonación total del Padre, dejando voluntaria y agradecidamente regalarse profusamente por el Padre, consumado todo ello tanto en la espontaneidad como en la "obediencia" absoluta (es decir, en el querer corresponder) al Padre: ambas cosas en el abandono confiado de la acción de gracias que corresponde a la medida sin medida de la esencia divina. El "no" de la criatura, en medio de esta prodigalidad divina, representa una especie de convulsión sobre sí misma, a la que, sin embargo, el flujo del amor ha superado siempre" (58).

Según la Teológica "Cristo puede ser definido aquí, con Máximo el Confesor y Buenaventura, como medium inter pure absolutum et pure contractum" (59), lo cual para Nicolás de Cusa significa que: "el Logos, como Dios y como hombre, es el amado absolutamente por el Padre; por lo cual, en tanto que toda realidad mundana queda "replegada" en la unión hipóstatica, "todo ser creable" puede ser amado de igual modo en el Hijo...el Espíritu, en cuanto connexio del amante (amans) con el que para él es "digno de amor" (amabile) es también quien reúne todo lo mundano

(56) TD III 303 (4, 301): Deshalb kann auch der Sohn die Absolutheit der Gottheit nicht anders sein und besitzen als im Modus des Empfangs dieser Einheit von Allmacht und Unmacht vom Vater her, welcher Empfang gleichzeitig das Sich-Gegebensein(die absolute Voraus-Setzung jedes möglichen Geliefertwerdens an die Welt) und die sohnliche Danksagung (Eucharistie) für das gleichwesentliche Gottsein einschliesst.

(57) TD III 303 (4, 302): Die besagte Verdankung ist das ewige Ja zum (Sich-)Gegebensein als gleichabsoluter Gott, ein Ja zur Ur-Kenosis des Vaters als Einheit von Allmach t(des Alles-gebenKönnens) und Unmacht (da nichts anderes wahrhaft mächtig ist als die Gabe).- Cf. H I 18s (G 1, 24): Sogar Platon ist hinter das Urphänomen zurückgegangen, indem er sich eine Seele ausdachte, die erst in einer zweiten Zeit in die Materie fiel; begreiflich, da er die Einheit des sich im Tode Auflösenden anders nicht retten zu können vermeinte, als indem er sie in eine abgetrennte (abstrakte, ab-solute) Geistigkeit setzte: Um der Freiheit und der Würde des Geistes willen machte er das Ursprüngliche zu einem Abgeleiteten und wurde zum Vater all derer, die anstelle des "Symbols"(Wahr-zeichen) eine "Allegorie" (Anders-rede) gesetzt haben, und all derer, die sich aus einer ganz überflussigen und nur scheinbar wissenschaftlichen Einstellung heraus fragen, wie (psychologisch) und mit was für vermeintlichen "Schlüssen" die Seele aus ihrer Innerlichkeit denn nur in die sogenannte Aussenwelt hinauszugelangen vermag. HOLZER V., Christologie de la figure (Gestalt) et christologie de la kénose chez Hans Urs von Balthasar, Revue des science religieuses 79 (2005) 249-278.

(58) TD III 306 (4, 305): Bis ans Ende der Wahrheit gehen heisst für den Sohn: auf die restlose Selbsthingabe des Vaters adäquat antworten durch willig-dankbares Sich-verströmen-Lassen durch den Vater, vollzogen sowohl in der absoluten Spontaneität wie im absoluten "Gehorsam" (als Entsprechen-Wollen) dem Vater gegenüber: beides in eucharistischer Gelöstheit, die den grenzenlosen Ausmassen des göttlichen Wesens entspricht. Das kreatürliche Nein ist innerhalb dieser Verströmung ein auf sich zusammengekrampfter Punkt, über den die Strömung der Liebe immer schon hinaus ist..

(59) TL II 194 (2, 205):Mit Maximus Confesor und Bonaventura kann Christus hier al "medium inter pure absolutum et pure contractum" bezeichnet werden.. 
en el medium absolutum en el mediator absolutus" (60)...finalmente, desde el puro "poder ser" (posset) se puede comprender todo lo que de algún modo es, que tiene su presupuesto en este incomprensible "poder" absoluto" (61). Así, las categorías cusánicas básicas de complicatio-explicatio-contractum-absolutum, pliegue y despliegue, siguen siendo determinantes de todo lo demás (62).

\section{d. El Espíritu Santo, diferencia infinita, siempre abierta entre el Padre y el Hijo}

Para Balthasar en la Teodramática: "Entre el don que engendra y la disponibilidad (a todo perdón) que agradece existe una correlación. Esta, colocándose por encima de lo totalmente otro que separa es... la manera de ser lo absoluto que se proyecta como un "nosotros" (63). "Es la identidad del don que da y del don que se recibe y que se reconoce pura y simplemente como don; don que no puede ser tal más que en la medida en que atestigua, mantiene abierta y enfatiza la diferencia infinita entre el Padre y el Hijo; en este sentido, tal don, dentro de la diferencia, es no solamente presupuesto, sino ya la unión activa del amor insuperable" (64).

Según la Teológica: "La posibilidad última de tal "devenir", de tal "génesis", la buscaremos... en el autodesposeimiento generador del Padre en el Hijo y de ambos en el Espíritu, autodesposeimiento que lo mueve a proseguir su propio movimiento absoluto en libertad en su creación. Está claro que solo la suprema potencia divina era capaz de tal forma de entrega amorosa" (65)...Esta situación se reviste de una seriedad absoluta .... y el justo debe ser sumergido en ella absolutamente, de forma más profunda que todos sus hermanos" (66). "Pero hay algo más: el Espíritu Santo es "esta exuberancia del amor, un fenómeno no solo del mundo natural, no solo del amor humano, sino del Ser absoluto...la cumbre incomprensible e insupera-

(60) TL II 194(2, 206): als der Logos sowohl als Gott wie als Mensch der vom Vater absolut Geliebte ist, weshalb, sofern alles Welthafte in die hypostatische Union hinein "eingefaltet" wird, "alles erschaffbare Sein" im Sohn gleicherweise geliebt werden kann. Wiederum ist der Geist als "connexio" des Liebenden (amans) mit dem für ihn "liebenswerten"(amibile) auch der Einsammler alles Weltlichen in das "medium absolutum" oder in den "mediator absolutus".

(61) TL II 195 (2, 207):schliesslich, vom reinen "Können-Sein"(posset) her kann alles irgendwie Seiende begriffen werden, das seine Voraussetzung in diesem unfassbarena absoluten Können hat.

(62) TL II 198 (2, 210): So bleiben die cusanischen Grundkategorien von complicatio-explicatio, contractum-absolutum, Einfaltung und Ausfaltung allebestimmend.

(63) TD III 303 (4, 302): Die Entsprechung von zeugender Hingabe und verdankender Bereitschaft (zu jeder Vergebung) über das trennende Ganz-anders hinweg ist-im dichsteten Glaubensgeheimnisdie als Wir sich ergebende Weise, das Absolute su sein:

(64) TD III 303(4, 305): die Identität der gebenden Gabe und der sich-empfangenden und verdankenden Gabe als Gabe schlechthin, die diese selbst nur sein kann, indem sie die unendliche Differenz von Vater und Sohn bezeugt, offenhält, befeuert, um innerhalb der Differenz nicht nur die Voraussetzung, sondern schon die Einigung der nicht überholbaren Liebe zu sein.

(65) TL II 259 (2, 274) Die letzte Möglichkeit solchen "Werdens", solcher "genesis" werden wir, wie schon öfter wiederholt, immer wieder in der innertrinitarischen "genesis", in der zeugenden Selbstentäusserung des Vaters zum Sohn und beider zum Geist hin suchen, die ihn bewegt, seine eigene absolute Bewegung in Freiheit in seine Schöpfung hinein fortzusetzen. Es ist klar, dass nur die höchste göttliche Macht einer solchen Form deren Liebveshingabe fähig war.

(66) TL II 268 (2, 283) Völligen Ernst gewinnt diese Situation in seinem Eingetauchtsein in die allmenschliche Versuchung, die als "Erprobung" gerade den Gerechten Gottes nie erspart worden ist(Vgl.Jdt 8, 25-27) und in die der Gerechte schlechthin tiefer eingetaucht werden muss als alle seine Brüder. 
ble del amor absoluto: Deus semper major no solo para nosotros, sino para Dios mismo" (67).

El teólogo suizo afirma que "De lo dicho por Tomás puede sacarse la conclusión de que el "modus existendi" de Dios (De pot.9, 2 ad 2), puesto que solo es determinable relacionalmente y por tanto se contrapone uno a otro, es en su diversidad "siempre más grande" que "cuanto se pueda pensar en realidad". Pero este distanciamiento infinito solo sería expresable en correlación con la absoluta cercanía en la esencia, pues cada una de las personas divinas es idéntica a la única naturaleza divina...deducimos de lo dicho solo una cosa: también para Tomás es necesario que el Espíritu Santo tenga ...su propio e incomparable "tropos hyparxeos" o "modus existendi" (68).

Por cierto, "El Hijo en modo alguno revela económicamente al Padre solo "per modum intellectus", sino que, como muestra suficientemente Juan, a través de su amor absoluto al Padre y a los hombres como amados por el Padre, revela primordialmente el amor del Padre. En este sentido, el Espíritu debería llamarse "donum doni", el amor dado al mundo por el Padre en el Hijo es como tal "derramado en los corazones", mediante el don del amor como Espíritu. Precisamente así, ...ninguno de los dos modos económicos de darse necesita denotar una relación primaria con la criatura; esta se enraíza en las íntimas relaciones de amor de Dios mismo" (69). De este modo, "Lo importante aquí es retener la unidad de ambos aspectos de la misma hipóstasis del Espíritu; en cuanto fuego más íntimo del amor del Padre e Hijo, es el conocimiento absoluto del amor desde dentro; pero, en cuanto producto, fruto, de este amor, es simultáneamente -como amor- el testimonio objetivo de que este amor tiene lugar eternamente" (70).

(67) TL III $146(3,161)$ : Er ist dieses Über-schwingen der Liebe, ein Phänomen nicht nur der WeltNatur, nicht nur der menschlichen Liebe, sondern des absoluten Seins... der unfassbare und unüberschreitbre Gipfel der absoluten Liebe ist: Deus semper major nicht nur für uns, sondern für Gott selbst. - Resulta ilustrativo el ejemplo del embarazo cf. TL III 146(3, 161-162).

(68) TL III $125(3,139)$ zieht aus dem von Thomas über die göttlichen Personen Gesagte die Folgerun, dass ihr modus existendi (De pot.9, 2 ad 2), weil nur relational bestimmbar und deshalb einander entgegengesetzt, in seiner Verschiedenheit "immer noch grösser" ist, als er "überhaupt gedacht werden kann". Aber diese unendlcihe Abhängigkeit sei nur in Korrellation zur absoluten Nähe im Wesen aussagbar, da jede der göttlichen Personen mit der einen göttlichen Natur identisch ist... folgern wir aus dem Gesagten nur eines: auch für Thomas braucht, ja kann der Heilige Geist nicht in der gleichen Weise als Person vorgestellt werden, wie wir uns Vater und Sohn als solche vorstellen, ; jede göttliche Hypostase hat ihren eigenen unvergleichbaren "tropos hyparxeos" o "modus existendi".

(69) TL III 149 (3, 164-165): Keineswegs offenbart der Sohn ökonomisch den Vater nur "per modum intellectus", sondern er offenbart, wie Johannes genugsam zeigt, durch seine absolute Liebe zum Vater und zu den Menschen als den vom Vater geliebten, primär die Liebe des Vaters...Insofern müsste der Geist "donum doni" heissen: die vom Vater im Sohn der Welt geschenkte Liebe wird als solche durch das Geschenk der Liebe als Geist "in die Herzen eingegossenen. "Gerade so wird der Geist nochmals, und nunmehr auch vom Innertrinitarischen her, als der geschenkte Ausleger des göttlichen Geschenks(das der Vater uns mit dem Sohn macht) erwiesen, und weil das Geschenk des Sohnes selbst schon Offenbarung der Liebe war, kann diese Auslegung durch den Geist wieder nur als Einführung in die Liebe geschehen. Beide ökonomischen Weisen des Sichschenkens brauchen, nach dem Gesagten, keine primäre Beziehung zur Kreatur zu besagen, die letztere wurzelt in den innern Liebesbeziehungen Gottes selbst.

(70) TL III 224 (3, 242): Das Wichtige ist hier, die Einheit beider Aspekte der gleichen Hypostase des Geistes festzuhalten: als der innerste Band der Liebe von Vater und Sohn ist er die absolute Kenntnis der Liebe von innen, aber als das Produkt, die Frucht dieser Liebe ist er -als Liebe- 
En síntesis, siendo el origen fundante de las afirmaciones absolutas no un motor inmóvil que está en la punta de la pirámide del ser, sino que se encuentra más allá del ser como amor que se concreta en la libertad infinita, evoca una índole dramática que se conserva en su concreción siempre oscilante entre polos desproporcionados. ¿Cómo se concreta tal oscilación si no por una participación en la donación absoluta, siempre inacabada y por eso analógica?

\section{PARTICIPACIÓN ANALÓGICA EN LA DONACIÓN ABSOLUTA DE DIOS SIEMPRE INACABADA}

La posibilidad de hacer afirmaciones absolutas en una sociedad pluralista no puede basarse en el ser unívoco ni equívoco, sino solo analógico, es decir, emerge oscilando entre lo absoluto y lo relativo, oscilación que Balthasar comprende a la luz del ser en cuanto "plenitud atravesada por la nada". En esto radica la doble tarea de la Iglesia: "no dejar que la verdad se fragmente por su pluralidad, sino incluirla en su propia unidad "pleromática" (71).

\section{a. La oscilación analógica del absoluto en lo relativo}

Cuando Balthasar pregunta ante "la pequeña parábola” (Mt 13, 46), “¿dónde se encuentra en el mundo algo tan precioso que valga la pena abandonarlo todo por ello sin el menor escrúpulo? ¿Acaso podría ser esta única cosa lo informal, el Absoluto, que disuelve desde dentro la forma del yo espiritual?" (72), resalta la peculiar comprensión dual del ser, contrapuesta a lo informal, designado aquí como lo absoluto. Cabe ver cómo tal comprensión del ser se concreta en una visión que supera la articulación informal de lo absoluto por medio de la entrega al Espíritu Creador.

La entrega al "Creator Spiritus”

En Gloria Balthasar contrapone la actitud propia de la fe de "abandonarse místicamente al Absoluto, entendido no solo como fundamento originario que sobrepasa toda forma mundana, la pone en cuestión o, más aún, la destruye", a aquella de "entregarse confiadamente al Creator Spiritus, al Creador desde el principio, el

gleichzeitig das objektive Zeugnis dafür, dass diese Liebe ewig stattfindet(das Kind als Zeugnis eines stattgehabten zeitlichen Liebesaktes der Eltern ist nur ein blasses Abbild davon), und indem der Geist beides gleichzeitig ist, kann er als der ewige Anfacher der göttlichen Liebe gelten, die sich gerade, weil die Liebenden dauernd die überhinaus-liegende Frucht erkennt, sich niemals so erschöpfen kann, wie blosse zwischen menschliche Liebe diese Gefahr der Erschöpfung ausgesetzt ist.

(71) TL III 238 (3, 257): Darin liegt die bis ans Ende der Welt nicht säuberlich unterscheidbaren Doppelbewegung und Doppelaufgabe der Kirche: einmal von sich weg zu den Völkern zu gehen und sie die christliche Wahrheit so zu lehren, dass sie sie verstehen und annnehmen können (die Frage der "Inkulturation), sodann durch ihre Vielheit die Wahrheit sich nich aufsplitten zu lassen, sondern sie in ihre eigene "pleromatische" Einheit einzubergen.

(72) H I 24(G 1, 29ss): denn wo auf der Welt ist etwas so kostbar, dass man bedenkenlos alles übrige fahren lassen dürfte, und das Eine wäre dennoch nicht das Gestaltlose, Absolute, das folgerichtig zuletzt die Gestalt des geistigen Ich von innen her auflöst? 
cual... no quiere... que el mundo...pierda su identidad ...sino que tiende a poner de manifiesto la forma creadora... obra suya, y...del hombre en una actitud de acogida, de asentimiento, de entrega" (73)...."una forma que emana inequívocamente de la forma de la encarnación divina" (74).

Esta verdad la explicita Balthasar a través de preguntas decisivas, que conducirán a la verdadera comprensión de lo absoluto, pues: ... ¿el ser está necesitado de los entes y los entes del ser? ¿No estamos ambos atravesados por la nada?”, y continúa "El poder ser, el haber sido admitidos ¿no es también para el ser como para mí, un primum? ¿no será que él es glorioso solo en virtud de su indigencia?¿No estará tan en calma solo porque se le ha permitido entrar...en nosotros? ¿No estamos entonces los dos oscilando y no es acaso esta oscilación la realidad libre, la realidad no condicionada? ¿Pero cómo podrá esta doble interdependencia, por tanto, este condicionamiento, mostrar algo absoluto?" (75)...Pero ¿para refutar sin rodeos lo que el espíritu finito se imagina que es una necesidad y una absolutidad?... entonces, "lo que nosotros percibimos como lo más bello en la esencia contingente y dual del mundo - la oscilación en sí y recíprocamente, no apremiada por nada, que abarca y fundamenta todas las necesidades justas y satisfactorias- ¿no debería ser de una manera inconcebible, lo que de nuevo y de distinto, una vez más, encontramos en Dios?" (76). Lo absoluto, entonces, remonta al interior de Dios y como tal requiere de un nuevo lenguaje.

(73) H I 32-33(G 1, 37): Sache des Glaubens ist es, dem Absoluten nicht allein als einem alle Weltgestalt übersteigenden, und sie alle infragestellenden, ja zerstörenden Urgrund mystisch sich anheimzugeben, sondern im Glaubens-Vertrauen sich zugleich dem Creator Spiritus anzuempfehlen, dem Schöpfer von Anbeginn, der, soviel immer an der Mensch-und Weltgestalt aufzulösen bleibt, im letzten nicht auf indische Weltzertanzung, sondern auf schöpferische Gestalt zielt. Diese Gestalt ist dann freilich sein Werk, das des Menschen nur insofern, als dieser sich dem göttlichen Wirken ohne Widerstreben, zulassend, beistimmend, erlaubend zur Verfügung gestellt hat...Gestalt, die unverkennbar aus der Form der göttlichen Inkarnation stammt".

(74) H I 33(G 1 38): Das Gegenteil dessen, was man erwarten würde, wenn ein begrenzter Mensch sich in zentral-personaler Hingabe an das schlechthin Grenzen-und Gestaltlose hingibt: nämlich neue Geistgestalt, eingemeisselt in den Stein der Existenz selber.

(75) H III I II 964(G 5, 586): wo wäre das Licht, wenn wir(alle) nicht wären, um es zu sehen?Braucht es uns dennoch? Aber nein, ich, wir alle, sind ihm gegenüber "zufällig": wir alles zusammen sind nicht zureichende Auslegung des Seins; es ist frei, sich noch unendlcih anders zu zeigen, für unendliche Andere zu lichten.Trotzdem was wäre Licht, wenn keiner es sieht? Sind wir also doch beide bedürftig? Das Sein der Seienden und die Seienden des Seins? Nichten wir beide? Ist das Sein-dürfen, das Eingedlassensein, wie für mich, auch für das Sein ein Erstes? Wird es glorreich erst inkraft seines Be-dürfens? Ist es gelassen nur, wei es eingelassen sit -in uns? Sind wir also beide schwebend, und ist diese Schwebe das Abgelöste, Un-bedingte? Doch wie kann das doppelte Aufeinander-angewiesensein, also Bedingtsein zusammen ein Absolutes ergeben?“

(76) H III I II 965(G 5, 586): So müssen wir, zögernd, beinah wider unsern Willen, die vierte Öffnung der Differenz ansetzen: jenseits der immer noch bedingten, gegenseitig angewiesenen Freiheit des Seienden zum Sein wie des Seins, im Seienden ungebunden zu lichten: eine unbedingte, höchstens durch sich selber bedingte Freiheit, undurch nichtet, actus purus, eine Freiheit, die zunächst nur darum angesetzt wird, damit das Licht der Offenheit zwischen dem Sein und dem Seienden ein freies, ungenötigtes Licht verbleibe, damit als das einzelne Wesen nicht untersinke in die Nötigungen eines Explikationsprozesses, und das Sein seine Freiheit nicht einbüsse in der gleichen "Odyssee" seiner kosmischen Evolution zu sich selber...Aber wenn das Kostbarste, was am Sein gewahrt werden muss, nur durch Gott gewahrt werden kann: sein Wunder-und Herrlichkeitscharakter, muss dann nicht Gott in überschwenglicher Weise Hort und Hirt dieser Herrlichkeit sein: in unmittelbarer Widerlegung dessen, was der endliche Geist sich unter Notwendigkeit und Absolutheit vorstellt? Ist dann nicht das, was wir am kontingenten 
El nuevo lenguaje de lo absoluto

Balthasar profundiza en la Teodramática lo absoluto cuyo "primer presupuesto es que "junto a" o "dentro de" la absoluta libertad divina, existe otra libertad no divina y creada, que en un sentido verdadero participa en la consistencia de la libertad divina..." con "La pregunta sobre cómo entonces es posible tal relación allí donde Dios como lo absoluto es "todo" y nada puede caer fuera de lo absoluto, y cómo ulteriormente, presupuesta la comprensión bíblica de Dios, la creación en cuanto tal es "buena" y sin embargo la libertad creada puede perderse al margen de Dios, constituye como la puerta de entrada a todo lo que sigue?" (77). En efecto, "hemos de preguntar cómo Dios, el absoluto y omnisciente por esencia, puede dejarse afectar..." (78), ya que, "Claro que esta dimensión absoluta no es concebible más que en unión con la otra dimensión de la relatividad... para poder cogerlo y poseerlo, necesita del asentimiento jovial y amoroso" (79).

Esto requiere de un lenguaje adecuado, pues: "Tal plenitud... no puede reducirse a un nuevo lenguaje de palabras puntuales, porque entonces los sujetos naturales y finitos no llegarían a entender estas "palabras" que les urgen desde el absoluto ...Si Dios mismo quiere comunicarse a sus criaturas, hay que suponer forzosamente entonces que al hablar se abre a sí mismo y comunica su propio ser absoluto y que, con tal motivo, capacita asimismo al espíritu creado para captar una tal comunicación como lo que es y significa, es decir, como participación en lo absoluto" (80). Explica el teólogo suizo: "El absoluto, al volverse hacia su criatura, no llega a alcanzar esencialmente más que cuando la eleva hasta Él, por encima de ella misma y de todo su condicionamiento esencial, y cuando le garantiza una acogida y un derecho de ciudadanía en la esfera de lo absoluto. En otras palabras: una tal comuni-

gezwieselten Wesen der Welt als das Schönste empfinden: das durch nichts genötigte Schweben, in sich und zueinander, das alle berechtigten und befriedigenden Nezessitäten umgreift und grundlegt, in einer unbegreiflichen Weise dasjenige, was wir, noch einmal neu und anders, in Gott finden?

(77) TD II I 56 (2, 61): ist dessen erstere Voraussetzung, dass "neben" oder "innerhalb" der absoluten göttlichen Freiheit andere, nicht göttliche, geschaffene Freiheit existiert, die in einem wahen Sinn am Selbststand der göttlichen Freiheit teilnimmt...Die Frage, wie denn ein solches Gegenüber dort möglich ist, wo Gott als das Absolute "alles" ist und nichts aus dem Absoluten herausfallen kann, wie ferner, das biblische Gottverständnis einmal vorausgesetzt, die Schöpfung als solche "gut" ist und troztdem geschaffene Freiheit sich von Gott weg verlieren kann, bildet wie das Einganstor zu allem folgenden.

(78) TD II I 64 (2, 69): die Frage muss-nochmals-gestellt werden, wie Gott, der Absolute und wesenhaft Vollkommene und Allwissende, sich überhaupt von einem andern Standpunkt betreffen lassen kann.

(79) TD II 1 202(2, 206): Freilich ist dieses Absolutsmoment nur denkbar, wenn verbunden mit dem andern der Relativität: Um das Rechte (und damit sich selbst) zu wollen, bedarf die Freiheit der Wohlberatenheit (consilium), um es auch ergreifen und besitzen zu können, der freudig-liebenden Zustimmung (complacentia).

(80) TD II I 365(2, 371): Solche Erfüllung, falls sie erfolgt, kann kein blosses Sprechen in transienten Worten sein, denn die natürlichen endlichen Subjekte würden solche vom Absoluten her zu ihnen dringende "Worte" weniger verstehen als der Mensch eine fremde Sprache. Die Sprache Gottes ist nicht die der Geschöpfe; wenn die letzteren etwas zu verstehen meinten, so hättten sie das gesprochene ins Innergeschöpfliche transponiert. Will Gott sich selbst seinen Geschöpfen mitteilen, so muss vorausgesetzt werden, dass er sprechend sein eigenes absolutes Wesen eröffend mit-teilt und zu diesem Behuf den geschafffenen Geist befähigt, eine solche Mit-teilung auch als das, was sie ist und meint, als Teilgabe am Absoluten aufzufassen. 
cación del absoluto tiene que ser a un tiempo conforme a su ser (esencial) y conforme a la palabra (espiritual, clarificante)" (81).

Pero no es solo el lenguaje y sus expresiones verbales los que están en juego aquí para Balthasar, pues "La absoluta unicidad del Dios simple no puede ser participada por la criatura más que a través del desdoblamiento de los principios de la unidad: en primer lugar, la unidad del ser en la pluralidad de las esencias, después (en la esfera de la corporalidad), la unidad de la especie en la pluralidad de los individuos" (82). De esta manera, el teólogo suizo recuerda: "En el amor absoluto se reconoce la existencia de actos libres que arrancando del mundo son... remitidos a un apreciable acontecimiento en el interior del amor absoluto y libre. Y en el mismo movimiento en el que el Hijo por obediencia revela este acontecimiento intradivino, hace ver cuál es la actitud justa del hombre ante Dios (más aún, “en” Dios) (83)... la hondura de la autorrenuncia en el servicio es la entrada del acontecimiento absoluto de libertad en el mundo creado" (84). En efecto, "En el hombre ha quedado depositado un fermento que procede de lo absoluto, que por ello quebró la vinculación de la humanidad a la naturaleza cósmica y le otorgó una libertad, y con ello un elemento de absolutez que sigue conservando por don de Cristo, aun cuando se desgaje de su origen" (85).

Advierte Balthasar: "Mientras que hasta el presente al hombre le parecía que su existencia "aherrojada" en el ser no podía deducirse por necesidad de un principio absoluto ...está en condiciones de reconocerse como alguien que ha sido coengendrado en la gracia juntamente con el Hijo absoluto; la relación que le liga a este origen es la propia del amor absoluto paternal y engendrador, que...inserta en el hecho de las procesiones intradivinas..." (86). "Nadie se convierte contra su volun-

(81) TD II I 366(2, 371): Das sich zum Geschöpf herabneigende Absolute erreicht das Geschöpfliche wesentlich nur, wenn es dieses über sich selbst und seinen ganzen Wesensbestand zu sich emporzieht, ihm Einlass und Heimatrecht in der Sphäre des Absoluten gewährt. Anders gesagt: eine solche Selbstmitteilung des Absoluten muss zugleich seinshaft (wesentlcih) und worthaft (geisthaft, erklärend) sein.

(82) TD II I 381 (2, 387): Die absolute Einmaligkeit des einfachen Gottes kann nicht anders kreatürlcih partizipiert werden als in der Verzweiung der Einheitsprinzipien: zunächst Einheit des Seins in der Vielheit der Wesen, dann(im körperlichen Bereich): Einheit der Gattung in der Vielheit der Individuen.

(83) TD II II $20(3,27))$ : man erkennt in der absoluten Liebe freie Vollzüge, die von der Welt her in der Sophia (“ökonomisch") unterscheidbar sind, aber auf ein unfassliches Geschehen innerhalb der absoluten freien Liebe selbst zurückweisen. Und im selben Zug, in dem der Sohn als Gehorsamer dieses innergöttliche Geschehen offenbart, enthüllt er auch des Menschen rechte Haltung vor Gott, nein: in Gott: Dienst bis zur Selbstvergessenheit, um Gottes "Talente" in der Welt fruchten zu lassen.

(84) TD II II 20 (3, 27): die gehorsame Distanz des Geschöpfs zu seinem Schöpfer und Meister wird durchsichtig auf die innergöttliche Distanz des Sohnes zum Vater im Geist: die Tiefe dienenden Selbstverzichts ist der Einlass des absoluten Freiheitsgeschens in die geschöpfliche Welt. cf. SACHS J., R., The Holy Spirit and Christian Form, Gregorianum 86 (2005) 378-396.

(85) TD II II 23 (3, 31): Ein Ferment ist in ihn hineingesenkt, das aus dem Absoluten stammt, das des die Bindung der Menschheit an die komische Natur löste und ihr eine Freiheit und darin einen Absolutheitsbezug gab, den sie auch in der Ablösung vom Ursprung, von Christus beiberhält.

(86) TD II II 32(3, 41):Während dem Menschen bisher seine ins Sein"geworfene" Ex-sistenz mit keiner Notwendigkeit aus einem absoluten Prinzip ableitbar erschien... darf sich jetzt als ein mit dem absoluten Sohn in Gnaden Mit-Gezeugter erkennen; die Relation, die ihn mit diesem Ursprung verbindet, ist eine solche der absoluten väterlichen und zeugenden Liebe... ist insofern einbezogen in das Geschehn innergötttlicher Vorgänge. Para una visión actual de la gracia bajo 
tad en hijo amoroso del Padre celestial. El hombre puede libremente elegir cuál es la libertad que prefiere: la de un puro origen a partir de sí mismo... o la de la actitud de agradecimiento continuo por el propio ser dirigido a la libertad absoluta, la cual ya desde siempre ha abierto a la finita el espacio en el que puede realizarse a sí misma: en Cristo" (87).

Recuerda Balthasar: "Al principio no había más que... uno absoluto que por esencia se bastaba a sí mismo y que no necesitaba de nada y otro relativo consciente de su finitud y de que no se bastaba a sí mismo. ¿Se puede concluir a partir de esta contraposición que es posible y real una interacción entre ellos? ¿En el hecho de que lo relativo no sea deducible radica de verdad el postulado de que lo absoluto ha de ofrecérsele como espacio que haga posible su perfeccionamiento?...Se puede pensar, sin caer en contradicción, una relación de lo absoluto con algo ajeno a él? En el caso de que se acepte la no existencia de este ámbito de relaciones, no le quedan al relativo más que dos caminos para lograr su perfeccionamiento: o su autodisposición en lo absoluto... o el intento de absolutizarse en el marco de lo relativo (88).

La analogía interior entre verdad infinita y finita

Sostiene Balthasar en la Teológica, que todo cobra "pleno sentido solo a la luz de la interior analogía de toda la verdad entre verdad infinita y finita, divina y mundana. Puesto que la verdad divina, en tanto verdad de una intimidad absoluta, sigue siendo necesariamente misterio en su revelación, toda verdad mundana tiene en sí algo de este carácter misterioso. Y todo ello de tal modo en propiedad al ser mundano, quien puede administrarla en una propia y personal intimidad de un modo libre y espontáneo, sin que, no obstante, deje de seguir siendo algo dado en propiedad, como una participación en la absoluta intimidad de la verdad divina de la cual

un enfoque balthasariano cf. GARCÍA C., "Una mirada a la gracia": Nota bibliográfica, Burgense 47 (2006) 501-520; PÉREZ DE LABORDA Alfonso (ed.) Una mirada a la gracia. El Escorial 2005, Facultad de Teología San Dámaso, Madrid 2006, 316 pp. http://www.apl.name/Alfonso/ El_Escorial_2005.pdf

(87) TD II III $33(3,42)$ : Keiner wird gegen seinen Willen zu einem liebenden Kind des himmlischen Vaters. Der Mensch kann in Freiheit wählen, welche Freiheit ihm lieber ist: die eines reinen Ursprungs aus sich selbst...oder die eines Sich-immer-neu-Verdankens der absoluten Freiheit, die der endlcihen deshalb auch je schon den Raum geóffnet hat, in dem sie sich selber vollenden kann: "en Christoi" - Cf. TD II II 111(3, 119): Sofern Jesu "Stunde" absolut einmalig ist, sieht man nicht, welche Rolle sie im Leben der Nachfolgenden spielen wird; TD II II 159 (3, 165): wenn Jesu Bewusssein einer absoluten (göttlichen) Sendung mit seinem Ichbewusstsein zusammenfallen soll: wie kann das Kind Jesu je zum Selbstbewusssein erwacht sein, ohne gleichzeitig -wenigstens implizit- von seiner Sendung gewusst zu haben?

(88) TD II II 37(3, 47-48): Anfänglich standen sich bloss ein wesentlich selbstgenügsames unbedürftiges Absolutes und ein seiner Endlichkeit bewusstes, sich selbst nicht genügendes Relatives gegenüber: kann man aus diesem Gegenüber schliessen, dass eine Interaktion zwischen ihnen möglich und wirklich ist? Liegt in der Unabschliessbarkeit des Relativen das Postulat, dass das Absolute sich ihm als Ort seiner Vollendbarkeit darbieten muss?...Ist eine Beziehung des Absoluten zu etwas ausser ihm überhaupt ohne Widerspruch denkbar? Wird die Nichtexistenz eines Beziehungsraumes angenommen, dann bleiben dem Relativen zwei Wege, seine Vollendung zu erstreben: entweder der seiner Selbstaufhebung im Absoluten...oder der des Versuches, sich innerhalb des Relativen zu verabsolutieren. 
recibe su misterioso carácter" (89)....Por eso toda asimilación por participación de la criatura en la absoluta y soberana libertad del querer divino que se revela en ella y por encima de ella" (90).

Según Balthasar, el hombre: "Elevando sus ojos hacia Dios, su relatividad se abre hacia lo absoluto en la originaria actitud de la entrega" (91). La inclusión del ser y del saber contingentes dentro del ser y del saber absolutos significa necesariamente que todo ser y toda conciencia mundana están desvelados ante lo absoluto....Parece casi una profanación de este misterio de la verdad el hecho de que la verdad pueda presentarse desnuda, sin velos, ante lo absoluto, casi, de nuevo, como aquella verdad puramente objetiva...La verdad absoluta no es precisamente la esfera de la verdad universal, anónima, accesible a cualquiera. Es la esfera de la verdad absoluta y personal de Dios y por tanto también la esfera de lo absolutamente henchido de misterio" (92).

En síntesis: los opuestos absolutos y relativos requieren de una oscilación desproporcionada; anticipada por la absoluta la libertad relativa logra consistencia, hasta dramaticidad, en sus múltiples expresiones ónticas y verbales, que atestiguan la posibilidad de las afirmaciones absolutas en una sociedad pluralista, que invita a verificar el equilibrio entre lo absoluto y lo relativo y su posible perversión.

\section{a. El equilibrio oscilante entre lo absoluto y lo relativo en la gracia absoluta}

Para Balthasar la oscilación entre lo absoluto y lo relativo se produce por el hecho de que ambos polos se rebasan mutuamente, tendiendo a un equilibrio, sostenido por la gracia absoluta en Cristo, recapitulación del universo.

\section{Cristo, la recapitulación del universo}

Para Balthasar no cabe duda en Gloria: "Que Jesucristo es la forma central de la revelación...Sin embargo, la libertad que se manifiesta en Cristo es la libertad del Dios no coaccionado por nada, que es absoluto y descansa en sí mismo, no obstante, por pura benevolencia, se liga para siempre e indisolublemente a la criatura a través de la unión hipostática, a fin de manifestarse y hacerse presente en ella" (93).

(89) TL I 261s $(1,226)$ : das alles wird erst sinnvoll im Lichte der inneren Analogie alles Wahrheit zwischen unendlicher und endlicher, göttlicher und weltlicher Wahrheit. Weil die göttliche Wahrheit, als die Wahrheit einer absoluten Intimität notwendig in jeder Offenbarung Geheimnis bleibt, darum hat jede weltlichen Wahrheit etwas von diesem Geheimnischarakter an sich.

(90) TL I 275(1, 236): Darum kann jede teilnehmende Angleichung der Kreatur an Gott nur in einer Einfügung ihrer kreatürlichen Freiheit in die absolute souveräne Freiheit des göttlichen Willens bestehen, der sich in ihr und über ihr offenbart.

(91) TL I 306 (1, 260): Im Blick auf Gott öffnet es seine Relativität zum Absoluten hin in der urprünglichen Haltung der Hingabe.

(92) TL I 306; 307(1, 265):Die Einfassung des kontingenten durch das absolute Sein und Wissen besagt nun aber notwendig, dass alles weltliche Sein und Bewusstsein vor dem Absoluten enthüllt ist...Es scheint fast wie eine Entweihung dieses Geheimnisses der Wahrheit zu sein, dass sie vor dem Absoluten schleierlos nackt daliegen soll, beinahe wieder wie jene reine sachliche Wahrheit...Die absolute Wahrheit ist gerade nicht die Sphäre der allgemeinen, anonymen, jedermann zugänglichen Wahrheit.

(93) H I 146-147(G 1, 143): Dass Jesus Christus die zentrale Gestalt der Offenbarung ist, um die alle übrigen Momente der Heilsoffenbarung kristallisieren und sich angliedern, hat das christliche 
Quiere decir que "En la medida en que Dios se adueña en Jesucristo de ambas dimensiones no solo para prolongarlas más allá de sí mismas al Absoluto, sino para anudar sus dos extremos divergentes en una figura única, nos muestra que lo lleva a su plenitud justamente en lo que tiene de más humano, ya lo identifiquemos con lo más elevado o con lo más profundo del hombre. En la medida en que los extremos del hombre se tocan, el medio se ajusta perfectamente..., en la figura de Cristo que la hace recapitulación del universo" (94).

\section{El equilibrio entre lo absoluto y lo relativo}

Cuando Balthasar comenta en la Teodramática la existencia de "Un cúmulo de posibilidades tanto históricas como prácticas para producir una relación e incluso una especie de "equilibrio" entre lo absoluto y lo relativo", advierte que no se trata de "fijar esa relación oscilante a una concepción religiosa determinada o para hacer que se anquilose en una ideología de sentido contrario" (95), sino "La vía de la concretización pasa por probar que la intrínseca finitud de la existencia no permite realizar cualquier forma de la relación absoluto-relativo...de modo que en el mundo finito se originan tensiones acerca de la relación con lo absoluto" (96), con ejemplos preclaros como el niño, en el cual se alcanza algo así como la realización inesperada de lo absoluto" (97), o como el arte que "está cerca de ese lado de lo absoluto que se llama gracia, regalo gratuito" (98) y también en cuanto

Denken von jeher gewusst und doch vielleicht in der Glaubenslehre nicht eindringlich genug beachtet...die Freiheit jedoch, die in Christus erscheint, ist die des durch nichts genötigten, in sich absoluten und ruhenden Gottes, der sich aber dennoch aus freier Huld für immer und unauflösbar in der hypostatischen Union mit der Kreatur verbindet, um in ihr zu erscheinen und sich darzustellen.

(94) H I 458s (G 1, 427-428):Indem Gott in Jesus Christus sich beider Dimensionen bemächtigt, um sie nicht nur über sich ins Absolute zu führen, sondern die beiden auseinanderstrebenden Enden zu einer einzigen Figur zusammenzufügen, zeigt er, dass er Mensch werdend, den Menschen nicht vergewaltigt, sondern ihn gerade in seinem Menschlichsten vollendet, mag dieses Menschlichste nun des Menschen Höchstes oder Tiefstes sein.Indem des Menschen Extreme sich berühren, wird alles Dazwischenliegende mit rund, Nichts braucht ausgelassen, von nichts braucht abstrahiert zu werden...Un doch kann ein so rundes und vollendetes Menschliche sich nur in der Einwohnung Gottes ereignen: in der Einigung des Grösst-Unendlichen und Kleinst-Unendlichen , die Nikolaus von Kues wie Pascual als die Figur Christi sahen, der eben damit zur abschliessenden Figur des Universums wird.

(95) TD III 97(4, 100): Eine Fülle von theoretischen und praktischen Möglichkeiten, ein Verhältnis oder gar eine Art "Gleichgewicht" zwischen dem Absoluten und dem Relativen herzustellen... dieses schwebende Verhältnis auf eine bestimmte religiöse Weltanschaung festzulegen oder sie zu einer entgegengestzten Ideologie erstarren zu lassen.

(96) TD III 98(4, 101): Der Weg der Konkretisierung führt über den Nachweis, dass die innere Endlichkeit des Daseins ihm nicht gestattet, jede gültige Form des Verhältnisses Absolut-Relativ zu verwirklichen, weil jede dieser Formen selbst endlich ist und eine Gegenform zum Antipoden hat, die eine ebenso relative Berechtigung beanspruchen kann, so dass in der Welt Spannungen um das Verhältnis zum Absoluten entstehen.

(97) TD III 99(4, 102): Wird die Einzeugung ins Leibhaftige ernst genommen, so erreicht die Natur über die Absicht der Vereinigung hinweg ihren Zweck, das Kind, in welchem gewiss so etwas wie das unverhoffte Gelingen eines Absoluten sich offenbart, das sich aber bald von den Eltern weg in die nachfolgenden Geschlechter verläuft.“

(98) TD III 100(4, 103): Kunst, grosse Kunst hat einen Sonderplatz unter den menschlichen Anstrenugen ausgesparrt, sie steht jener Seite des Absoluten nah, die man Gnade, umsonstige Verschenkung nennt. 
“Todo drama humano se despliega como el intento de buscar y poseer un punto de equilibrio, eternamente inestable, entre lo que hay que realizar bajo la norma de lo absoluto y la caducidad" (99).

Según Balthasar "puede aventurarse la fórmula cristiana de que el hombre, el primer Adán, fue creado con vistas al segundo. No solo con vistas a Dios...sino al Dios-hombre, en el cual se produce el equilibrio, inalcanzable por el hombre entre lo absoluto y lo relativo, ... que solo puede ser alcanzado con el predominio absoluto de Dios y por ello solo a partir de él" (100). Para Balthasar "Un segundo comportamiento fundamental se refiere .... a los otros... Si esta relación cae bajo una norma absoluta, la de la verdad y el bien a la vez, se plantea la exigencia de comprender la justicia y la misericordia o el perdón" (101). "Pero en cuanto levanta su mirada a la norma de lo absoluto... la muerte vuelve a hacer presente... el misterio insoluble, la íntima contradicción de su ser...Desde la desnuda facticidad de la paradoja... descrita... como "lo absoluto en lo relativo" ¿debe conformarse sin más con la paradoja como lo hizo el Antiguo Testamento?" (102).

Esto implica según Balthasar que "Mi muerte...que es absolutamente segura y sin embargo incierta...es algo totalmente diverso de un "caso", es el más solitario de los encuentros con mi yo... a la luz de lo cual todo lo que se viva en el tiempo... pasa bajo la luz de la absoluta seriedad" (103). Continúa Balthasar: "pues en realidad la muerte ha realizado de un modo ilimitado, ... la paradoja clave de la existencia que debe reconocer y realizar lo absoluto en lo relativo (104). "Y si se realiza efectivamente la imposibilidad de que lo absoluto no solo aparezca en la finitud, sino que él mismo acabe por hacerse finito, puede igualmente acontecer lo que es incomprensible para el hombre, que lo finito en cuanto tal quede insertado en lo definitivo, en lo eterno...Porque a pesar de todo en lo finito se introdujo, por su captación de lo verdadero y lo bueno, un rayo de absoluto...y ninguno de sus mo-

(99) TD III 101(4, 104): Alles menschliche Drama dreht sich um das Finden und Besetzen des ewig ungesicherten Gleichgewichtspunktes zwischen dem unter der Norm des Absoluten zu Verwirklichenden und der Vergänglichkeit.

(100) TD III 101 (4, 104): Von hier aus kann die christliche Aussage gewagt werden, dass der Mensch, der erste Adam, auf den zweiten hin geschaffen worden ist. Nicht nur auf Gott hin... sondern auf den Gottmenschen hin, in welchem das vom Mensch unfindbare Gleichgewicht zwischen dem Absoluten und del Relativen hergestellt ist, und zwar gewiss von Gott her

(101) TD III103s(4, 106): Eine zweite Grundgebärde betrifft...den andern...Einmal tritt dieses Verhältnis unter die absolute Norm:die des Wahren und Guten zugleich.Und nun erhebt sich die Foderung des Ausgleichs zwischen Gerechtigkeit und dem Erbarmen oder der Vergebung.

(102) TD III 108(4, 110-111): Sofern er aber der nach der Norm des Absoluten Aufblickende... führt der Todo nochmals und härter als je vor das unauflösliche Geheimnis, den innern Widerspruch seines Daseins zurück...Von der nackten Faktizität jenes Paradoxes, das anfangs als "das Absolute im Relativen" beschrieben wurde: Soll man sich schlicht in das Paradox bescheiden, wie es das Alte Testament in seiner klassischen Zeit tat...?

(103) TD III 112 (4, 114): zu meinem eigenen, absolut sichern und doch zeitlich ungewissen Nicht(mehr) sein, ist mein Tod etwas anderes als ein "Fall", er ist einsamste Begegnung mit meinem (Nichtmehr-) Ich, von der her alles in der gewährten Zeit noch gelebte in das Licht des absoluten "Ernstes" rückt.

(104) TD III 119(4, 121): das zentrale Paradox des Daseins, das Absolutes im Relativen erkennen und verwirklichen soll. 
mentos puede capturar plenamente... esa luz que se ha introducido" (105), lo cual evoca el problema del existencial sobrenatural (106).

Balthasar llega a concluir desde "el hecho de la propia subjetividad...al carácter subjetivo del absoluto, aunque... pasa por la experiencia de los padres que despiertan al niño a la autoconciencia y requiere una ulterior reflexión que distinga al sujeto absoluto de la subjetividad de los hombres...esta última se manifiesta en una intimidad evidente, (y) también lo absoluto puede manifestarse sin problemas de modo abierto..." Esta "conclusión" subyace lógicamente a toda autocomunicación sobrenatural de Dios y es igualmente una de sus condiciones de posibilidad. Hay que hablar de "conclusión", pues no se da una intuición directa de Dios, si bien... se presenta como un directo mirar a través de"... (107). Sin duda, "se trata de un conocimiento incoativo en el que en cualquier caso se capta lo divino como lo absoluto, y por ello como lo que fundamenta todo lo mundano, como principium et finis (DS 3004), a la vez como incomprensible (DS 3001) a partir de lo mundano (Rm 1, 19s)” (108).

Para Baltasar, "Es decisivo que esta "conclusión" arranca en su primer movimiento de la autoposesión del espíritu y que puede haber sido en buena medida provocado y capacitado para esta autoposesión desde dentro; y hasta el hecho de que el espíritu finito haya sido provocado para comprender su contingencia hace que en la representación que elabora acerca de lo absoluto sean dominantes precisamente los momentos que Pablo presentó en este contexto como "potencia eterna" frente a la impotencia que deviene en el tiempo y que vive temporalmente, y asimismo la "divinidad eterna" que frente a lo relativo da relieve al momento de lo absoluto".

La mayor desemejanza

En Teológica Balthasar advierte que: "al concluir esta reflexión se podría preguntar si un tratamiento así de los trascendentales (que en Dios rigen absoluta-

(105) TD III 121s(4, 123): Und wenn dies Unmögliche, dass das Absolute nicht nur in Endlichkeit hineinscheint, sondern selbst endlich wird sich verwirklicht, dann kann auch das für das Dasein Unvorstellbare sich ereignen, dass das Endliche als solches in das Endgültige, Ewige einbezogen wird...Weil doch in das Endliche kraft seiner Einsicht in das Wahre und Gute immer ein Strahl vom Absoluten her einfiel...und kein Augenblick das einfallende Licht ganz einfangen...

(106) TD III 129-131(4, 128-129).cf. NEUFELD K.H., Ausdrückliche Auseinandersetzung.Zu offenen Fragen zwischen Karl Rahner und Hans Urs von Balthasar, Gregorianum 86 (2005) 366-377.

(107) TD III 128 (4, 129): Ferner doch wohl auch den Schluss vom eigenen Subjektsein...auf das Subjektsein des Absoluten, auch wenn.. über den elterlichen Mitmenschen geht, der das Kind zum Selbstbewusstsein aufruft, und erst eine weitere Reflexion das absolute Subjekt sich vom mitmenschlichen abheben lässt. Und eben weil das letztere sich in einer offenbaren Intimität kundtut, kann auch das Absolute zunächst fraglos als offen kundgetan erscheinen...Ein solches "Kennen" liegt in dem besagten spontanen "Schluss" vom eigenen und mitmenschlichen Bewusstsein auf den Subjektcharakter des Absoluten.Dieser "Scluss" liegt logisch jeder übernatürlichen Selbsterschliessung Gottes voraus und ist auch eine Bedingung ihrer Möglichkeit.Von "Schluss" muss gesprochen werden, da keine direkte Intuition des göttlichen Urgrundes vorhanden ist.

(108) TD III 129(4, 130): ...Es geht um eine inchoative Kenntnis, in der auf jeden Fall das Göttliche als das Absolute und damit für alles Welthafte Grundlegende, als principium et finis (DS 3004), wenn auch zugleich als das "Unbegreifliche" (DS 3001) erfasst wird ...aus dem Welthaften "Erkennbare" (Rm 1, 19s). 
mente el ser y también caracterizan a las hipóstasis como tales) pone suficientemente de relieve la "major dissimilitudo" entre Dios y criatura. Desde luego, es cierto que aquí la analogía entre el ser absoluto y subsistente y el ser creado libremente por él, que solo llega a la subsistencia en esencias finitas, se presupone más que se trata temáticamente; sin embargo, basta una mirada a la Trinidad necesaria en el ser divino y a la contingencia de los miles de millones de individuos en el ser humano, para hacer que se ilumine de inmediato esta desemejanza mayor" (109).

En síntesis: la dimensión gratuita de las afirmaciones absolutas resalta con fuerza en la argumentación balthasariana, no solo en sus momentos de creaciones artísticas, sino también en lo que se refiere a la caducidad de la vida y de la muerte. De ahí dicha argumentación en una posible perversión de lo absoluto a través de sus concreciones posibles.

\section{c. La concreción de lo absoluto y su perversión posible}

Debido a que lo absoluto se encuentra ligado a la experiencia primaria de la autoposesión en libertad por parte del hombre, es vivida como una capacidad de ser poderoso... hace aparecer toda libertad como autoposesión, emerge la posibilidad de una perversión de lo absoluto.

\section{Posibilidad de una absolutización}

Baltasar ha rechazado en Gloria la interpretación del concepto teológico alejandrino de la gnosis... como un "saber" en el sentido moderno, ya a la manera hegeliana, como una elevación "a la idea del Absoluto"... (110), advierte el peligro "que se da entre dos personas, que puede absolutizarse y volverse demoníaco, cuando lo finito se entrega infinitamente a lo finito, incluyendo su salvación eterna"....Tiene que ser el amor cristiano que descansa en la unión hipostática de Cristo y conjuga dos realidades eternamente incompaginables por el hombre: el amor a un ente y el amor al ser" (111).

(109) TL I 164 (1, 175): Nun könnte am Schluss dieses Denkschritts gefragt werden, ob eine solche Behandlung der Transzendentalien (die in Gott sowohl das Wesen durchwaltet wie die Hyopostasen als solche kennzeichnen) die "major dissimilitudo" zwischen Gott und Geschöpf hinreichend zur Geltung bringt. Dass hier die Analogie zwischen dem absoluten, subsistierenden Sein und dem von ihm frei geschaffenen, nur in endlichen Wesenheiten zur Subsistenz gelangenden Sein mehr voraussetzt als thematisch behandelt wurde, ist gewiss richtig; doch genügt ein Blick auf die notwendige Trinität im göttlichen Sein und die Zufälligkeit der Millarden Individuen im menschlichen Sein, um diese grössere Unähnlichkeit sogleich aufleuchten zu lassen.

(110) Cf. O'REAGAN C., Balthasar and Gnostic Genealogy, Modern Theology 22 (2006) 609-650.

(111) H I 186 (G 1, 176): Aber nicht irgendeiner Liebe, wie der zwischen Mensch und Mensch, die, verabsolutiert, dämonisch werden muss (weil dann ein Endliches sich an ein anderes Endliches unendlich übergibt, mitsamt seinem ewigen Heil)...sondern gerade nur der christlichen Liebe, die auf der hypostatischen Einheit Christi aufruht und das menschlich ewig Unvereinbare zusammenknüpft: die Liebe zu einem Seienden mit der Liebe zum Sein. 
La separación del poder de la bondad

Balthasar en la Teodramática advierte que para insertar lo absoluto en el relativo "No se tiene en cuenta la mayoría de las veces que lo absoluto debe ser pensado tanto como el poder sin más cuanto como el bien que irradia y se comunica, pues solo uniendo los dos presenta la verdad...Así no deja ver más que un momento de lo absoluto, mientras que mantiene oculto otro, tal vez más esencial, con lo que se engaña a sí mismo y a los demás acerca de la esencia verdadera de lo absoluto. Cuando se impone mediante el sometimiento...lo finito (en) algo cuasi absoluto... se convierte en algo demoníaco y se niega a reconocer que lo absoluto es, por encima de lo finito, un sol de bien y de justicia en su sentido más sublime" (112), "el sol de lo absoluto", cuyos rayos transfiguran todas las abominaciones" (113).

Cabe recordar, según Balthasar que el hombre no tiene más que un fin sobrenatural y de que, al conocer su carácter no absoluto, se puede como comprender a sí mismo (en su razón y en su libertad) como una imagen de lo absoluto que posee una esencial orientación a su modelo" (114). De ahí que "cuando la libertad finita se atribuye a sí misma su ser regalada (lo que en realidad pertenece al absoluto y es inseparable de él) se despoja al absoluto de algo que le corresponde para atribuirlo a la libre disposición de la libertad finita. Esto quiere decir tres cosas:

"En primer lugar, que el dinamismo que remite la libertad finita a la infinita se apropia solo del aspecto del poder, pues la bondad del absoluto (en cuanto es experimentable como el que dona) no puede ser encajada en la autonomía... la libertad que se pone como absoluta y autónoma priva a la libertad finita no solo de su armonía con la libertad absoluta, sino también consigo misma... la solidaridad en el amor se convierte en puntos absolutos en mutua separación...

"Lo segundo: la contradicción debe quedar escondida, pues se trata precisamente, para aquel que no quiere reconocerse como debido a, de su identidad absoluta... Este silenciamiento resulta más fácil si con la elección de la propia autonomía como absoluta se elige un bien supremo... y de la presunción de que es bueno pueden establecerse y realizarse innumerables bienes... que se derivan de ese bien y a él se hacen retornar. Incluso a esa liberación de una "heteronomía" respecto a lo absoluto se la puede establecer precisamente como la condición de posibilidad del despliegue de todos los bienes intramundanos, hasta llegar a hacerlo creíble.

(112) TD III 99(4, 102): Dabei wird zumeist nicht bedacht, dass das Absolute sowohl als die Macht überhaupt wie las das Gute, die ausstrahlende, sich mitteilende Güte überhaupt gedacht werden muss und nur in dieser Einheit die Wahrheit darstellt...Und in dieser Weise kann sie nur ein Moment des Absoluten aufscheinen lassen, während sie ein anderes, vielleicht wesentlicheres verhüllt lässt und damit sich selbst wie die Mitwelt über das wahre Wesen des Absoluten täuscht. Wo sie sich durch Unterdrückung durchsetzt...weil sie ein unvergleichlich Bestes, QuasiAbsolutes im Endlichen darstellt ...ist sie schon dämonisch geworden und will nicht mehr wissen, dass das Absolute über allem Endlichen eine Sonne des Guten, der Gerechtigkeit in deren erhabenstem Sinn ist.

(113) TD III 100 (4, 103):Der Strahl des Ruhms, von der Sonne des Absoluten ausgeliehen, verklärt alle Greuel.

(114) TD III 151 (4 151): der Mensch...somit kein anderes Endziel hat als ein übernatürliches, und dass er, der um sein eigenes Nichtabsolutsein weiss, sich (in seiner Vernunft und Freiheit) als ein Bild des Absoluten verstehen kann, das eine wesentliche Hinordnung auf das Urbild besitzt. 
El tercer aspecto se infiere de lo dicho: como el poder asumido tiene que recurrir a la mentira para cubrirse, esta mentira no puede suprimirse a sí misma...Al adueñarse la libertad finita de este poder realiza dos gestos: separa el poder del bien que la regala y se pone a sí misma contra el bien absoluto y así bajo su juicio... el que se ha adueñado del poder absoluto es dominado precisamente por el poder absoluto, de modo que no se puede defender de él como quisiera" (115): "El mal posee en sí una especie de atracción que empuja hacia algo siempre peor; marca el ritmo hacia la posesión absoluta de la razón, para lo que usa todos los medios a su disposición" (116). Pero, "la libertad absoluta infinitamente autónoma-contradice intrínsecamente la arrogancia de la libertad finita de concebirse como infinita. Si se concibe como definitiva esta contradicción entonces esta es el infierno" (117).

\section{La verdad pura y su absoluto ser-en sí}

En la Teológica el teólogo suizo advierte una perversión sutil respecto de la verdad, comprendida "desde ciertas constelaciones de verdades que dan por resultado, en su especial composición, mezcla y coloración, una especial y única síntesis correspondiente, por ejemplo, al fatal momento del horóscopo que se sigue de una especial constelación. El hombre está continuamente dentro de tales constelaciones de verdades... Jamás encuentra la verdad en su puro, absoluto ser en sí, sino siempre

(115) TD III 149(4, 150): Deshalb wird, wo die endliche Freiheit sich ihr Geschenktsen selber zueignet, etwas zum Absoluten Gehöriges, von ihm Untrennbares, diesem enteignet und der Selbstverfügung der endlichen Freiheit zugeteilt. Dies besagt nun ein Dreifaches.Erstens wir von der Dynamik, die die endliche Freiheit auf die unendliche verweist, nur die Seite der Macht angeeignet, da die Güte des Absoluten, sofern es als schenkendes erfahrbar wird, der Autonomie nicht eingefügt werden kann.Autonomie Freiheit, absolut gesetzt, kann sich nur selber als die Norm des Guten verstehen.Sie hat, mit anderen Worten, das Gute in ihrer macht, was ein innerer Widerspruch ist, weil im Absoluten das Gute mit der macht identisch ist...Dieser von sich absolut-autonom setzenden Freiheit geheimgehaltene Widerspruch bringt die endliche Freiheit nicht nur um ihr Einverständnis mit der absoluten Freiheit, sondern auch um das mit sich selbst...Dieser innere Widerpruch überträgt sich notwendig auf jedes mitmenschliche Verhältnis, das aus einem solchen liebvender Solidarität zu einem solchen von einander abstossenden Absolutpunkten wird.

Das zweite ist damit schon berúhrt: der Widerpruch muss verhüllt werden, da es dem , der sich nicht verdanken will, gerade um seine absolute Identität geht...Diese Beschwichtigung fällt um so leichter, als man sich der Wahl der eigenen Autonomie als Absolutum ja ein(in der Welt) höchstes Gut wählt, von dessen Gut-dünken eine Unzahl abgeleiteter und ihm wieder zugeleiteter Güter, persönlicher und sozialer, gesetzt und verwirklciht werden kann. Ja, man kann die Befreiung von einer "Heteronomie" del Absoluten gegenüber geradezu als die Bedingung der Möglichkeit der Entfaltung aller innerweltlichen Güter hinstellen und dies(immer durch Selbstbeschwichtigung) glaubhaft machen.

Wieder lässt sich das Dritte aus dem gesagten ersehen:Da die angeeignete macht sich durch Lüge verhüllen muss, kann sich diese Lüge nicht selber aufheben... Indem sich die endliche Freiheit dieser macht bemächtigt, tut sie zweierlei: sie trennt die Macht von von der schenkenden Güte, sie stellt sich gegen das absolut Gute und damit unter sein Gericht...der sich mit der absoluten Macht Ermächtigende wird darin gerade von der absoluten Macht übermächtigt, so dass er sich ihrer nicht mehr nach seinem Belieben erwehren kann.

(116) TD III 152 (4, 153): Das Böse hat einen Sog zum Je-Böseren; die Rechthaberei des Sünders gegenüber der absoluten Wahrheit die er in der Lüge leugnet, hat den inneren Zug zu einem absoluten Rechtbehalten, so dass er auch alle verfügbaren Mittel zu diesem Ziel in Dienst nimmt.

(117) TD IV 274(5, 296s): die absolute... Freiheit...widerspricht ineinemfort die Anmassung der endlichen Freiheit, sich als unendliche zu verstehen.Wird dieser Widerspruch als endgültig gedacht, so ist er die Hölle. 
en esta especial selección, orientación, dirección, en este especial perfilamiento que lo constriñe a probarla en su contenido de verdad...El sentido auténtico, cualitativo de la situación, y toda su importancia aparecen a la luz solo cuando se dilucida a través del misterio del ser (existente)" (118).

Sintetizando, puede apreciarse la vulnerabilidad del equilibrio oscilante que puede establecerse entre los polos desproporcionados de lo absoluto y lo relativo, como también los peligros que acechan tal equilibrio. De ahí que cabe profundizar la concreción de dicha relación a la luz de la analogía de la donación y su gratuidad.

\section{c. La teología de lo Absoluto}

Para Balthasar, todo quehacer teológico radica en el "valor absoluto de la oración, es decir, en su Absolutheit (119), la cual remonta a que "la condición de suceso del amor absoluto exige muchas cosas que hay que introducir en el proceso de generación y de espiración; naturalmente en aquella eminencia que está por encima de todas las modalidades creaturales, pero cuyos arquetipos están en Dios" (120). "Reside aquí una imagen sombría del destino gracioso del hombre, llamado a realizar su libertad dentro del eterno intercambio del amor trinitario donde la libertad absoluta de una hipóstasis se da a las otras y se recibe de ellas" (121).

El bien absoluto

Balthasar precisa la dimensión teológica de lo absoluto en la Teodramática cuando afirma: "El intento de un hombre de excluirse de la vida trinitaria que en Cristo envuelve al mundo y de ser infierno en sí, permanece capturado por la curva de Cristo, y, en ese sentido, está determinado por la esencia y sentido de esta, que es el de comunicar al mundo la libertad del bien absoluto...y de llevar su multiplicidad a una unidad ordenada" (122). Por eso, "Todo esto debería iluminar los límites

(118) TL I 216-217 (1, 189): So erscheint das Perspektivische, wenn man es aus dem Standpunkt des Erkennenden erklärt und betrachtet.Man kann es aber auch aus gewissen Konstellationen der Wahrheiten heraus verstehen, die in ihrer besonderen Zusammensetzung, Mischung und Färbung eine besodere und einmalige Synthese ergeben, entsprechend etwa dem durch eine bestimmte Konstellation sich ergebenden schicksalshaften Augenblick im Horoskop. In solche Konstellationen von Wahrheiten hinein ist der Mensch fortlaufende gesetzt, in ihnen allein wird im Wahrheit kund und mit solchen hat er sich auseianderzusetzen.Er trifft die Wahrheit nie in ihrem reinen, absoluten An-sich-sein, sondern immer in dieser je schon gesonderten Auswahl, Zuwendung, Profilierung, die ihn zwingt, sie auf ihren Wahrheitsgehalt hin zu prüfen...Der echte, qualitative Sinn der Situation und damit ihre ganze Dringlichkeit tritt erst zutage, wenn man sie durch das in der Beschreibung der Personalität berührte Geheimnis des (Da-)Seins erläutert.

(119) TD IV 83-86(5, 94s).

(120) TD IV 85(5, 94): Die Ereignishaftigkeit der absoluten Liebe aber fordert vieles, was in den trinitarischen Zeugungs-und Hauchungsprocess hineingelegt werden muss, in jener Eminez natürlich, die über allen kreatürlichen Modalitäten liegt, deren Urbilder aber in Gott sind.

(121) TD IV 275 (5, 297): Hierin liegt ein schattenhaftes Bild der gnadenhaften Bestimmung des Menschen, seine Freiheit innerhalb des ewigen trinitarischen Liebesaustausch zu verwirklichen, worin die absolute Freiheit einer Hypostase immer sowohl der andern gegeben wie von ihr erhalten wird.

(122) TD IV 276s (5, 299): So betrachtet bleibt auch noch der Versuch eines Menschen, sich selbst aus dem in Christus die Welt in sich einholenden trinitarischen Leben auszuschliessem, um in sich Hölle zu sein, umfangen von der Kurve Christi, und insofern durch ihr Wesen und ihren Sinn 
internos y lo discutible de la idea de una autoelección absolutamente libre del hombre (en negación completa de Dios)" (123). "Dicho con otras palabras: quien quisiera elegir para sí el abandono total y demostrar con ello su absolutez frente a Dios se encontraría delante de sí con la figura de uno que está abandonado de forma más absoluta que él mismo" (124)... "ante una autoridad absoluta, entregado al único poder que manda aquí" (125).

Según Balthasar, "Tomás se suma a esta opinión cuando puntualiza diciendo que tal impecabilidad presupone tanto la visión del bien absoluto como la gracia que procede de él, pues la voluntad creatural sacada de la nada no podría adherirse definitivamente al bien con sus propias fuerzas. Pero ni la teología de Agustín... ni la teología escolástica... pueden decirnos gran cosa sobre qué pueden hacer los bienaventurados con esa libertad perfecta. La actuación de esta se hace visible solo desde una teología de lo absoluto, en la que aparece basada tanto la libertad infinita de autorrevelación como la consiguiente idea de novedad eterna, lo que se refleja luego en la criatura y en la libertad propia de ella" (126).

\section{La verdad absoluta}

Balthasar acota en la Teológica: "Jesús es el testigo de la verdad que es él.... Y, puesto que él como Palabra absoluta es también la verdad absoluta, la contradicción frente a él es también la no verdad, la mentira absoluta. Dia quiere decir en su sentido original "separado", desgarrado, por tanto dialéctica, dia-legein, significa contradecir, el surgir... de la hostilidad absoluta" (127). Para comprender esto "se

bestimmt, der da ist, die Freiheit des absoluten Guten der Welt mitzuteilen. Die Freiheit Christi allein ist mächtig, unsere Gebundenheiten zu sprengen und deren Vielfalt zu einer geordneten Einheit zu bringen.

(123) TD IV 277(5, 300): Dies alles sollte die innern Grenzen und die Fragwürdigkeiten des Gedankens einer absoluten freien Selbstwahl des Menschen (in restloser Absage an Gott) beleuchten.

(124) TD IV 284 (5, 307):" Anders gesagt: wer die vollkommene Verlassenheit für sich wählen und damit Seine Absolutheit Gott gegenüber beweisen wollte, träfe vor sich auf eine Gestalt eines, der absoluter verlassen ist als er selbst.

(125) TD IV 333(5, 357):(Ich stehe "auf einmal) vor einer absoluten Autorität, ausgeliefert der einzig regierenden Macht". -Por eso no hay ya una relación "más concreta" de mis pecados con Dios, sin solo una relación "absolutamente contradictoria; el pecado es ante Dios lo radical y absolutamente excluido" -von Speyer,

(126) TD IV 368(5 392): Und Thomas schliesst sich dem durchaus an, indem er näherhin feststellt, dass solche Unsündlichkeit sowohl die Schau des absoluten Gutes wie die von ihm ausgehende Gnade voraussetzt, da der aus dem Nichts gezogene geschöpfliche Wille sich nicht aus eigener Kraft endgültig im Guten festankern könnte. Aber was die Seligen mit dieser vollkommenen Freiheit anfangen können, darüber sagt uns die auf ein Ideal der "Ruhe" ausgerichtete Theologie Augustins, die auf ein Ideal der "Schau" festgelegte Theologie der Scholastik wenig. Ihre Bestätigung wird ersichtlich von einer Theologie des Absoluten her, in dem sowohl unendliche Freiheit der Selbstoffenbarung wie die daraus entspringende Idee ewiger Neuheit grundgelegt erscheint, was sich dann auch im Geschöpf und in der ihm eigenen Freiheit widerspiegelt.

(127) TL II 289 (2 305):In seiner Selbstauslegung im Fleisch exponiert sich der Logos aufs äusserste, sein Licht scheint in eine Finsternis, die "nicht begreift", was nicht blosses Nichtwissen, sondern Nichtwissen-Wollen bedeutet. Jesus ist der Zeuge für die Wahrheit, die er ist; einem Zeugen glaubt man oder man glaubt ihm nicht.Sein Zeigen des Vaters in sich selbst ist sein Sprechen, sein Spruch; nicht glauben, dass er Gott zeigt, ist der Wider-spruch gegen ihn. Und weil er als das Wort schlechthin auch die Wahrheit schlechthin ist, ist der Widerspruch gegen ihn auch die Unwahrheit, die Lüge schlechthin."Dia" heisst in seinem Ursinn "auseinander", "entzwei", deshalb heisst widersprechen, dia-legein, Dialektik das Aufklaffen des unversöhnlichen, Feindlichen schlechthin. 
debe tener siempre presente que la verdad, que... posee en toda su profundidad esta santidad de Dios trinitario, no es un principio ni unos hechos, sino revelación del amor absoluto" (128).

El amor absoluto

En el Epílogo el teólogo suizo constata: “... puesto que Cristo... se presenta a sí mismo... como interpretación del (supramundano) ser absoluto, lo hace completamente único, de modo que las estructuras mundanas de "forma y luz" (belleza) sirven hasta para la epifanía...del Absoluto. A partir de ahí se explica el doble acontecimiento:...la necesidad de la ascensión (la aparición debe desaparecer, a fin de que se haga comprensible que era realmente revelación del Absoluto), pero luego el Espíritu divino debe interpretar precisamente esta forma como la única aparición definitiva del Absoluto, del Hijo...Si ulteriormente la muerte (expiatoria) del Hijo se interpreta como el amor perfecto de Dios al mundo, se divisa una vez más en el Absoluto la ya insinuada análoga (supra)diferencia en la identidad de Dios, y con ello, la posibilidad de que una diferente "persona" divina (idéntica con el ser absoluto) entre en el lugar donde todo ser humano personal se fundamenta en la omniabarcante realidad (del mundo) y desde ahí "personaliza" al ser individual del hombre Jesús" (129).

Explica Balthasar: “...eso no puede resultar simplemente en virtud del ser común real (en el "esse non subsistens"), sino que el ser absoluto, siendo en la persona de Jesús, se debe regalar libremente desde sí -y exactamente esto es "gracia"- con el fin de que pueda verse la forma total de Jesús como revelación de Dios, lo cual ciertamente no excluye que se pretenda ahí la estructura humana racional del conocimiento. Y dicha estructura será ahí tanto más vigorosa cuanto más directa e indisimuladamente pueda... considerar toda particularidad del camino de la cruz en dirección hacia el amor absoluto de Dios que ahí aparece" (130).

(128) TL II 290 (2, 306) Man muss, um das Lügenhafte der Sünder gegenüber der Heiligkeit des dreieinigen Gottes zu sehen, stets vor Augen behalten, dass die Wahrheit, die der Ausleger Gottes ist, diese Heiligkeit des dreieinigen Gottes zu ihrer Tiefe hat; sie ist kein Satz und kein SachVerhalt, sondern Offenbarung der absoluten Liebe

(129) Ep 50 (62):Da sich aber Christus...zugleich sich selber als Auslegung des (überweltlichen) absoluten Seins vorstellt, macht ihn vollkommen einmalig, so, dass die weltlichen Strukturen von "Form und Licht" (Schönheit) selbst zur Epiphanie der oben erwähnten Struktur des Absoluten dienen. “... Daraus erklärt sich das Doppelte...die Notwendigkeit der Himmelfahrt (die Erscheinung muss verschwinden, damit verständlich wird, dass sie wirklich Offenbarung des Absoluten war), aber sodann muss der göttliche Geist gerade diese Gestalt als die einzig endgültige Erscheinung des Absoluten auslegen, des Sohnes...Wenn ferner der (Sühne-Tod) des Sohnes sich als die vollkommene Weltliebe des Vaters deutet, wird im Absoluten nochmals die schon angedeutete analoge (Über-) Differenz in Gottes Identität ansichtig, und damit die Möglichkeit, dass eine differente göttliche "Person"(identisch mit dem absoluten Sein) an den Ort tritt, wo alles menschliche Personsein in der allumgreifenden (Welt-)Wirklichkeit gründet und von dort her das einzelne Menschsein Jesu"personiert".

(130) Ep 51 (62): dass dies nicht einfach aufgrund des gemeinsamen Wirklichseins (im "esse non subsistens"), erfolgen kann, sondern dass sich dazu das in der Person Jesu wesende absolute Sein von sich her frei schenken muss-und genau dies ist "Gnade"-damit sie Gesamtgestalt Jesu als Offenbarung Gottes in den Blick kommen kann, wass jedoch nicht ausschliesst, dass die menschliche vernunfthafte Erkennisstruktur dabei mitbeansprucht wird.Und sie wird um so 
Si desde allí "En toda belleza hay un momento de la gracia: se me muestra más de lo que tenía derecho a esperar..." vale que "por eso se produce... la admiración de que "haya" ser en una abundancia que fluye inmensurable, pero que se vierte en entes y ahí llega a realidad perfecta. Pero los entes consuman, precisamente por el acto de ser, su individual iluminarse y mostrarse... en una "forma" cuyos momentos "se ponen" unos a otros, recta y manifiestamente, desde la unidad: lo coincidente en la unidad es tanto la luz como la forma...La gracia entitativa que actúa en todo esto es peraltada cualitativamente allí donde el Absoluto se ilumina y se forma acabadamente en los seres finitos; ante esta gracia por antonomasia... se requiere.... adoración" (131).

Para Balthasar, "lo 'bueno'; darse y decirse culminan en el absoluto darse, de tal modo que todo para sí se ha superado siempre ya en un para ti. Este absoluto darse solo puede ser entonces "generación" (dentro de la identidad divina), cuyo resultado solo puede ser total recepción y total devolución al origen; en donde el "amor" de la devolución no puede ser menor que el de la generación. De ahí se sigue que el unos-en-otros del amor produce, con poder igualmente (divino), aquella identidad de amor que, una vez más dentro de la identidad, es tanto el fruto como el definitivo alumbramiento de la absolutez del amor mismo. "Dios es amor" y nada más..." (132).

Por eso: "Cuando la persona del Hijo toma forma humana, para revelar (mostrando, diciendo y dando) este absoluto amor como "Palabra", entonces esta "Palabra" no habla más que del amor absoluto trino y uno, en doctrina, vida y cruz, en el juicio sobre toda negación del amor, juicio que se muestra a sí mismo como obra del amor...Pero tales afirmaciones parecen olvidar el problema principal: ¿cómo puede hacerse presente el Absoluto - de manera definitiva- en una efímera forma finita de vida? Desde el mundo parece esto imposible; pero ¿quién puede decir que tal forma

wirksamer dabei sein, je direkter und unverstellter sie das Phänomen Christi angehen kann...jede Einzelheit des Kreuzweges betrachten aus die darin erscheinende absolute Liebe Gottes hin.

(131) Ep 50 (62): Ein Moment der Gnade liegt in aller Schönheit: es zeigt sich mir mehr, als ich zu erwarten ein Recht hatte, daher das Staunen und die Bewunderung: Schon darüber, dass "es" Sein "gibt" in einer unmessbaren strömenden Fülle, die dennoch in Wesenheiten sich eingiesst und dort zu vollendeter Wirklichkeit kommt; auch in mir, der sich nicht mir, sondern ihm (zu meinem ewigen Erstaunen) verdankt. Die Wesen aber vollziehen, vom Seinsakt genötigt, ihr individuellles Sich-Lichten und Sich-zeigen(wie zum Dank dafür, dass ein Urgrund sie "sein lässt), in einer "Gestalt", deren Momente von der Einheit her richtig und offenbarend zueinander "gestellt" sind: das zur Einheit Zusammenfallende ist sowohl das Licht wie (im Ereignis) die Form. Die in alldem waltende seinshafte Gnade wird dort qualitativ überhöht, wo das Absolute im Endlichen sich selber lichtet und ausformt; angesichts dieser Gnade schlechthin, die nicht mehr Schönheit, sondern Herrlichkeit kundtut, ist nicht mehr nur Verwunderung und Entzücken erfodert, sondern Anbetung.

(132) Ep 72-73(87): Dabei dominiert jetzt zentral das "Gut" -Sich-zeigen und Sich-sagen kulmieren im schlechthinigen Sich-geben, so sehr, dass jedes Fürsich sich immer schon in ein Fürdich überstiegen hat; anders vom Vater zu denken wäre Arianismus. Dieses absolute Sich-geben kann dann nur "Zeugung" (innerhalb der Gottidentität) sein, deren Ergebnis nur totaler Empfang und totale Rückgabe an den Ursprung sein kann; darin kann "die Liebe" der Rückgabe nicht geringer sein als die der Zeugung. Daraus folgt, dass das Ineinander der Liebe gleich (göttlich) mächtig jene Liebesidentität hervorbringt, die, nochmals innerhalb der Identität, sowohl die Frucht wie das "abschliessende" An-den-Tag -Treten der Absolutheit der Liebe selbst ist."Gott ist die Liebe" und nichts anderes. 
de vida es desde Dios apriorísticamente imposible, porque encierra en sí una contradicción?" (133).

Balthasar concluye: Tal representación del amor absoluto de modo intramundano unifica de nuevo, sin esfuerzo y no dialécticamente, en su existencia, formas del amor que mundanamente nos parecen contrarias: trae en sí mismo la paz y la reconciliación de los enemistados (Ef 2,14ss), pero simultáneamente la espada...". "Si se supera la epifanía de Dios, este se convierte en el abismo y profundidad sin fondo, en el uno, en el ser absoluto... no puede pasarse por alto que todo en Cristo -la circuminsessio en él de todos los trascendentales, también en su polaridad intramundana- por ser Palabra del Padre en el Espíritu, siempre sigue siendo referencia a la riqueza del amor de Dios, donde... los trascendentales que aparecen en él son revelación de la vida trinitaria de Dios" (134).

\section{A MODO DE CONCLUSIÓN}

Verificamos la posibilidad de afirmaciones absolutas en una sociedad pluralista, no en el sentido de que los factores culturales socioeconómicos hacen posibles o no dichas afirmaciones, dándonos permiso para pronunciarlas o no, sino que estas afirmaciones mismas se acreditan en cuanto autoirradiación, autodonación y autodicción potentes y multifacéticas del único origen fundante, plural trinitario en una complejidad filosófico teológica impresionante. De esta manera, lo absoluto adquiere su "forma" propia dentro de la "situación" concreta, moldeada por el "seguimiento apasionado de Cristo". Las afirmaciones absolutas, por ende, encuentran su condición de posibilidad en la cuestión del ser, comprendido por Balthasar como "plenitud atravesada por la nada".

Un tal posse posible, pero siempre expuesto a la nada, evocado por el Vaticano I y II como una certeza alcanzable, allí donde razón y amor se complementan en su confluencia misteriosa a través de la estructura dual del ser -confluencia que se pervierte tan pronto, que el sujeto de dichas afirmaciones disocia el poder de la bondad y se encamina hacia una abstracción lógica conceptual, que tiende a ponerse absoluta a sí misma en cuanto identificación del ser con el concepto o con Dios, una tendencia latente -según lo visto- en Agustín y Maestro Eckhart u opuesta a la

(133) Ep 73 (88): Wenn die Hypostase des Sohnes Menschengestalt annimmt, um als "Wort" diese absolute Liebe zu offenbaren(zeigend, sagend und gebend), dann spricht dieses "Wort" von nichts anderem als der dreieinigen absoluten Liebe, in Lehre, Leben und Kreuz, im Gericht über alle Nichtliebe, das sich selbst als Werk der Liebe erweist...Aber solche Aussagen scheinen das Hauptproblem zu vergessen wie denn das Absolute sich-endgültig- in einer ephemeren endlichen Lebensgestalt zu vergegenwärtigen vermag. Von der Welt her scheint dies unmöglich; aber wer kann sagen, sie sei von Gott her apriori unmöglich, weil es einen Widerspruch in sich schliesst?

(134) Ep 74 (92) er stellt innerweltlich die absolute Liebe dar, in dem er Formen der Liebe, die uns weltlich konträr scheinen, wiederum mühelos und undialektisch in seiner Existenz eint: er bringt in sich selbst den Frieden und die Versóhnung der Verfeindeten(Eph 2, 14ff.), aber gleichzeitig das Schwert... Übersteigt man Gottes Epiphanie, wird er zum Ab-und Ungrund, zum Einen, zum absoluten Sein...darf nicht übersehen werden, dass alles in Christus-die circuminsessio in ihm aller Transzendentalien, auch in ihrer innerweltlichen Polarität-immer nur, da er Wort des Vaters im Geist ist, Verweis auf den Liebesreichtum Gottes bleibt, wobei, wie gezeigt, die in ihm erscheinenden Transzendentalien Offenbarung der dreipersonalen Lebendigkeit Gottes sind. 
fragmentación total del ser, presente en nuestra cultura contemporánea. Lo que hace crisis en estos extremos es, sin duda, una adecuada comprensión de la diferencia entre el ser y el ente -distinctio realis-comprensión elaborada por el pensamiento balthasariano en la medida en que este relativiza las afirmaciones absolutas, es decir, las pone en relación con las aspiraciones y nostalgias más vitales de la sociedad pluralista.

En efecto, la misteriosa "diferencia real" entre el ser y los entes se revela como aquel lugar originario de las afirmaciones absolutas, donde la belleza, la bondad y la verdad trasuntan en una unidad multifacética. Tales "vestigios del ser" -los trascendentales-, permiten pensar la pluralidad en la unidad, de tal forma que a la vez se verifica la certeza y no certeza matemática en las relaciones del ser humano con la realidad -relaciones siempre totales, pero desproporcionadas y por eso analógicas. Pese a que la verdad constituye el momento cumbre de esta analogía, su fundamento más originario es la bondad "más del ser", que como tal irradia a través del resplandor de la forma en su belleza indescriptible y se concreta en la donación permanente de sí mismo en cuanto analogia donationis.

Esta analogia donationis cuenta, sin duda, con el ímpetu natural hacia lo absoluto en el ser humano, pero dicho ser humano debe hacerse cargo de la gratuidad, comprendiendo este deseo natural como donado por una libertad absoluta. En efecto, tal libertad $S e$ autodona con aquellas características propias del Dios vivo, el Yo soy y la verdad joánica, aunque lo visto a nivel exegético todavía deja la sensación de que el Absoluto sería un ente que va al encuentro de otro ente, "pasando por encima del ser; como se podría concebir interpretando desde fuera de la filosofía el Antiguo Testamento". Recién allí donde se trató la universalidad de este acontecimiento absoluto en la persona de Jesucristo, es decir, la pluralidad convergente en la unidad, y el carácter "definitivo" de las afirmaciones magisteriales -afirmaciones fijas y a la vez por fijar, emergió la posibilidad de afirmaciones absolutas, acreditadas por Cristo, el Universal en el cual se concreta el Amor del Padre en el Hijo por el Espíritu Santo a todos los hombres.

El Amor revela entonces aquella absolutez, tan cercana y lejana a la vez, que posibilita las afirmaciones absolutas en una sociedad pluralista y que como tal es recibido también en contextos secularizados extremos. Así lo demuestra la recepción asombrosa de la Encíclica Deus caritas est de Benedicto XVI en todo el mundo, hasta en ambientes políticos, socioeconómicos muy dispares. Tal recepción inesperada de un documento papal a nivel mundial, demuestra no solo la validez de las afirmaciones absolutas en cualquier sociedad, sino también su fascinación permanente sobre el ser humano, quien, en definitiva, solo desea amar y ser amado. De esta manera, la posibilidad de afirmaciones absolutas en una sociedad pluralista queda excedida por aquel "cuánto más", que, en toda su dramaticidad, se origina en el amor absoluto de Dios Trino y Uno y como tal acredita nuestra esperanza.

\section{RESUMEN}

El estudio investiga la posibilidad de afirmaciones absolutas en una sociedad pluralista a partir de la cuestión del ser, fundamento absoluto de todo cuanto es y la índole plural de sus 
múltiples expresiones. Trata de dilucidar dicha posibilidad en la obra de Hans Urs von Balthasar, quien comprende el ser en cuanto "plenitud atravesada por la nada" y aborda el acontecer analógico en el ser, cual movimiento de un polo a otro, del ser al no ser y viceversa, de tal modo que la negatividad del no ser se torna positiva en la medida en que es don y el ser es comprendido en cuanto analogia donationis. Pretende verificar en qué medida tal analogia donationis, permaneciendo siempre analogia entis, posibilita afirmaciones absolutas en la sociedad pluralista, siguiendo la argumentación balthasariana, en tres pasos, elaborados sobre una base estadística, sorpresivamente extensa y multifacética, del campo semántico, que ocupa lo absoluto en la obra del teólogo suizo.

Palabras clave: absoluto, ser, analogía, donación, Balthasar.

\begin{abstract}
This study investigates the possibility of absolute affirmations in a pluralist society, starting off from the question of being, fundamental absolute of everything as is and the plural nature of its multiple expressions. The author attempts to resolve such a possibility from the work of Hans Urs von Balthasar, who understands being as "fullness pierced through by nothing", and addresses the analogical event in being -that pole-to-pole movement- from being to no-being and vice-versa, in such a way that the negativity of no-being is taken positively in the measure that it is gift, and being is comprehended in terms of analogia donationis. The author intends to verify in what measure such analogia donationis, always remaining analogia entis, makes possible absolute affirmations in a pluralist society, following the Balthasarian argument, in three steps, elaborated upon a statistical base, surprisingly extensive and multifaceted, of the semantic field, that occupies the absolute in the work of the Swiss theologian.
\end{abstract}

Key words: absolute-being-analogy-donation-Balthasar. 